\title{
A Genotype-Phenotype Study of High-Resolution FMR1 Nucleic Acid and Protein Analyses in Fragile $X$ Patients With Neurobehavioral Assessments
}

Dejan B Budimirovic ( $\sim$ dbudimi1@jhu.edu )

Kennedy Krieger Institute/Johns Hopkins Medical Institutions https://orcid.org/0000-0001-7263-5134

Annette Schlageter

Asuragen

Stela Sadic-Filipovic

Asuragen

Dragana Protic

University of Belgrade School of Medicine

Eran Bram

Asuragen

E. Mark Mahone

Kennedy Krieger Institute

Kimberly Nicholson

Asuragen

Kristen Culp

Asuragen

Kamyab Javanmardi

Asuragen

Andrew Hadd

Asuragen

Kevin Sharp

Rush University

Tatyana Adayev

Institute for Basic Research in DD, NY

Giuseppe LaFauci

Institute for Basic Research in DD, NY

\section{Carl Dobkin}

Institute for Basic Research in DD, NY

Lili Zhou

Rush University

William Ted Brown 
Institute for Basic Research in DD, NY

\section{Elizabeth Berry-Kravis}

Rush University

Walter E Kaufmann

Emory University

Gary J Latham

Asuragen

Research

Keywords: Autism Spectrum Disorder, Fragile X Syndrome, FMRP, FMR1, PCR

Posted Date: June 15th, 2020

DOl: https://doi.org/10.21203/rs.3.rs-34874/v1

License: (c) (i) This work is licensed under a Creative Commons Attribution 4.0 International License.

Read Full License 


\section{Abstract}

Background. Fragile X syndrome (FXS) is caused by silencing of the FMR1 gene, which encodes a protein with a critical role in synaptic plasticity. The molecular abnormality underlying FMR1 silencing, CGG repeat expansion, is well characterized; however, delineation of the pathway from DNA to RNA to protein using biosamples from well characterized patients with FXS is limited. Since FXS is a common and prototypical genetic disorder associated with intellectual disability (ID) and autism spectrum disorder (ASD), a comprehensive assessment of the FMR1 DNA-RNA-protein pathway and its correlations with the neurobehavioral phenotype is a priority.

Methods. We applied nine sensitive and quantitative assays evaluating FMR1 DNA, RNA, and FMRP parameters to a reference set of cell lines representing the range of $F M R 1$ expansions. We then used the most informative of these assays on blood and buccal specimens from cohorts of patients with different FMR1 expansions, with emphasis on those with FXS ( $\mathrm{N}=42$ total, $\mathrm{N}=31$ with FMRP measurements). The group with FMRP data was also evaluated comprehensively in terms of its neurobehavioral profile, which allowed molecular-neurobehavioral correlations.

Results. FMR1 CGG repeat expansions, methylation levels, and FMRP levels, in both cell lines and blood samples, were consistent with previous FMR1 genomic and protein studies. They also demonstrated a high level of agreement between blood and buccal specimens. These assays further corroborated previous reports of the relatively high prevalence of methylation mosaicism. Molecular-neurobehavioral correlations confirmed the inverse relationship between overall severity of the FXS phenotype and decrease in FMRP levels. Other intriguing findings included a potential relationship between diagnosis of FXS with ASD and very low levels of FMRP, compared to FXS without ASD.

Conclusions. The results underscore the link between FMR1 expansion, gene methylation, and FMRP deficit. The association between FMRP deficiency and overall severity of the neurobehavioral phenotype invites follow up studies in larger patient cohorts. They would be valuable to confirm and potentially extend our initial findings of a relationship between ASD and other neurobehavioral features and the magnitude of FMRP deficit. Molecular profiling of individuals with FXS may have important implications in research and clinical practice.

\section{Background}

Fragile X syndrome (FXS) is caused by a full mutation (FM, > 200 CGGs) expansion in the promoter region of FMR1. The expansion mutation leads to atypical methylation, transcriptional silencing, and ultimately deficiency of FMR1-encoded protein (fragile X mental retardation protein, FMRP) [1]. The degree of methylation is influenced by the number of tandem CGG trinucleotide repeats in the 5' UTR. Normal genotypes (up to 44 CGGs) and the majority of premutation genotypes (PM, 55-200 CGGs) are associated with an unmethylated or partially methylated gene that expresses $F M R 1$ transcripts [2] and its protein (FMRP) in brain and other tissues [3]. In contrast, in individuals with the FM genotype FMR1 is 
typically fully or mostly methylated and transcript and protein expression are markedly reduced. FMRP interacts with about $4 \%$ of total mammalian brain mRNAs $[2,4,5]$ and regulates many proteins involved in synaptic development and function [6]. Typical of an X-linked disorder, females with FXS often have a less severe phenotype consistent with the presence of a normal allele that can compensate for the silenced FM allele [7]. Levels of FMRP in the blood of patients with FXS have been positively correlated with cognitive performance, specifically intelligence quotient (IQ) and adaptive behavior [8-10].

FMR1 gene expansions are complex, exhibiting size and methylation variability (i.e., mosaicism); skewed $X$-inactivation may add on another layer of complexity in females. These factors may affect the level of FMRP deficiency and phenotypical severity [7, 11-13]. Both size and methylation mosaicism (MM) can vary in different tissues within an individual [14-16], which further complicates the interpretation of phenotypical heterogeneity. For example, previous studies have highlighted differences in FMR1 genotypes between blood cells (of mesodermal origin) and fibroblast or buccal epithelial cells (of ectodermal origin) from the same individual $[14,17]$. As FXS mainly affects the brain these discrepancies are highly relevant, where neurons and other cells have an ectodermal origin whereas FMR1 and FMRP assays are generally based on blood samples.

FMR1 genomic profiles are complex and merit characterizing in FXS. In particular, FMRP expression in brain is the ultimate factor determining severity of the neurobehavioral phenotype [18]. Intriguingly, it is estimated that $10-20 \%$ of normal FMRP expression is sufficient for a cognitive performance at the borderline IQ level [19]. Studies applying sensitive methods have revealed that many individuals with FM alleles are size and/or methylation mosaics. These individuals retain the capability of producing at least some FMRP as they are harboring both differentially methylated PM alleles and/or FM alleles [20-22].

In addition to genotypical and molecular phenotypical (i.e., FMRP) complexity, FXS is heterogeneous in its physical and neurobehavioral manifestations [23]. This is particularly evident in the range of neurobehavioral abnormalities associated with FM such as the most prevalent anxiety, hyperarousal, impulsivity and other attentional network deficits, aggression and self-injurious behaviour often accompanied by irritability [24]. FXS is also frequently comorbid with autism spectrum disorder (ASD; $50 \%$ of male and $20 \%$ of female) [25-27]. Indeed, evidence supports a partial overlap between the pathogenetic mechanisms that lead to FXS and ASD in the general population [28, 29]. Additionally, many proteins that interact with FMRP are also associated with idiopathic ASD [30-32]. Lower FMRP levels have also been documented in some research samples of individuals with FXS and ASD (vs. FXS only) and idiopathic ASD [33]. Thus, FMRP deficits may impact molecular pathways and synaptic processes [6] underlying some aspects of autistic behavior [29]. Importantly, greater severity and lower functioning is associated with ASD co-morbidity in FXS [26,34]. A higher prevalence of seizures, sleep problems, and co-occurring problem behaviors, in particular aggressive/disruptive behavior, is found in pediatric population with FXS and ASD than in FXS only [35]. Nonetheless, it is difficult to determine the selective contribution to ASD since most of these individuals with FXS have also lower cognitive performance [32]. The aforementioned heterogeneity and the difficulties in interpreting blood-based FMR1 and FMRP 
profiles in FXS quite compels the need to improve molecular assays and molecular-phenotypical analyses.

Namely, integration of diagnostic genomic data with complementary FMR1 assays and more accurate FMRP profiles is necessary [36]. The data integration enables to clarify relationships between genotype and protein expression and the neurobehavioral phenotype [37]. Such links may improve disease prognostics and characterization of response to pharmacological and other therapeutic interventions [11, 36], as well as help stratify patients with FXS in clinical trials [38]. Recently, a series of FMR7-based molecular methods quantifying genetic and epigenetic features of the mutation with greater sensitivity, specificity, and breadth have been reported [20, 21, 39-41]. These FMR1 assays can be applied across different specimen types, such as blood and buccal epithelium, and combined with FMRP measurements $[42,43]$. Specifically, advanced PCR-based methods can reliably amplify small and large FMR 1 repeat expansions, detect low-level repeat size mosaicism, determine the number and sequence context of sequences that interrupt the repeat tract, quantify X-inactivation, and measure skewed FMR1 gene silencing that was masked using less sensitive techniques such as Southern blotting $[11,17,20,21,39$, 44-46]. In addition, more precise FMRP assays allow a better delineation of the range of FMR1 protein levels and, consequently, more accurate FMR7-FMRP correlations [42, 43, 47]. This integrated approach was recently used to explore repeat instability in a reprogrammed stem cell model of fragile X-associated primary ovarian insufficiency (FXPOI) patients [42].

In the present investigation, we report results from a comprehensive evaluation of FMR1 and FMRP profiles, and their associations with the FXS neurobehavioral phenotype. We compared nine complementary assays for assessing FMR1 DNA, RNA, and protein using a reference set of wellcharacterized FMR1 cell lines. We then applied data from the most informative assays to examine for molecular-neurobehavioral relationships in an independent cohort of patients with FXS with and without ASD. In addition to these primary analyses, we also contrasted molecular profiles in matched blood and buccal specimens in order to include their value in informing FXS phenotypical variability.

\section{Methods}

\section{Participants}

Two cohorts were included in the molecular and molecular-phenotypical analyses. The first was a Reference Cohort of 11 individuals, with and without FXS, that provided whole blood specimens at Rush University Medical Center (RUMC) under approved Institutional Review Board (IRB) protocols. These five males and six females represented a range of FMR1 genotypes, from normal to FM; their samples were used to generate genomic DNA (gDNA) for different genomic studies [repeat-primed PCR (RP-PCR), methylation PCR (mPCR), AGG interruption analysis and Southern blot analysis] and to create lymphoblastoid cell lines and durable control material for evaluating, comparing, and contrasting FMR1 DNA and protein analyses. 
The second or Clinical Cohort consisted of 42 patients with a range of FMR1 expansions (Table 1), who were randomly recruited from a pool of patients assessed at the Kennedy Krieger Institute (KKI)'s Fragile X Program between 2013-2016. Table 1 presents an overview of the Clinical Cohort, including its demographic features. Detailed genomic profiling was performed for the subcohort of patients with FM (FM-ALL Subcohort, $\mathrm{N}=37$; Table 2); most of these participants also had FMRP measurements (FMFMRP Subcohort, $\mathrm{N}=31$; Table 1), detailed neurobehavioral assessments, and other genomic assays (Tables 2 \& 3). All protocols were approved by the Johns Hopkins Medicine's IRB.

Table 1. Characteristics of the Clinical Cohort

\begin{tabular}{|c|c|c|c|c|c|c|}
\hline \multirow[b]{3}{*}{ Gender } & \multicolumn{2}{|c|}{ Clinical Cohort } & \multicolumn{2}{|c|}{ FM-ALL Subcohort } & \multicolumn{2}{|c|}{ FM-FMRP Subcohort* } \\
\hline & $\mathrm{N}=42$ & & $\mathrm{~N}=37$ & & $\mathrm{~N}=31$ & \\
\hline & Male & Female & Male & Female & Male & Female \\
\hline $\mathrm{N}$ & 33 & 9 & 31 & 6 & 26 & 5 \\
\hline \multicolumn{7}{|l|}{ Age years } \\
\hline Mean (SD) & $14.4(11.9)$ & $14.7(10.9)$ & $14.7(12.6)$ & $11.8(7.3)$ & $13.8(11.9)$ & $13.2(7.2)$ \\
\hline Median & 10 & 10 & 10 & 10 & 9.5 & 10 \\
\hline Range & $2.6-47.1$ & $5-39$ & $2.6-47.1$ & $5-26$ & $2.6-47.1$ & $9-26$ \\
\hline \multicolumn{7}{|l|}{ Race, $\mathrm{N}$} \\
\hline Caucasian & 25 & 8 & 23 & 5 & 20 & 4 \\
\hline African American & 3 & 1 & 3 & 1 & 2 & 1 \\
\hline Asian & 4 & 1 & 4 & l & 3 & l \\
\hline Hispanic & 1 & l & 1 & l & 1 & l \\
\hline \multicolumn{7}{|l|}{ FMR1 expansions, $\mathrm{N}$} \\
\hline FM & 31 & 6 & 31 & 6 & 26 & 5 \\
\hline $\mathrm{PM}$ & 2 & 3 & 1 & I & I & 1 \\
\hline
\end{tabular}

Abbreviations: FM - full mutation, FMRP - fragile X mental retardation protein, $\mathrm{N}$ - number of participants, PM - premutation, SD - standard deviation.

*Detailed clinical neurobehavioral assessments of the FM-FMRP Subcohort are presented in Table 3. 
Table 2. Summary of materials and molecular analyses

\begin{tabular}{|c|c|c|c|c|}
\hline Materials & $\begin{array}{c}\text { DNA Genotype } \\
\text { Repeat Size Analysis }\end{array}$ & $\begin{array}{c}\text { DNA } \\
\text { Epitype Methylation } \\
\text { Analysis }\end{array}$ & $\begin{array}{c}\text { RNA } \\
\text { Expression } \\
\text { Analysis } \\
\end{array}$ & Protein Quantification \\
\hline Reference & GS-PCR/CE & mPCR & RT-gPCR & qFMRP \\
\hline \multicolumn{5}{|l|}{ Cohort } \\
\hline & GS-PCR/AGE RP-PCR/CE & & & \\
\hline \multirow{3}{*}{$\begin{array}{l}\text { Cell } \\
(11 / 11)\end{array}$} & AGG interruption PCR & & & \\
\hline & Sequencing & & & \\
\hline & Southern Blot & & & \\
\hline Clinical Cohort & GS-PCR/CE & mPCR & RT-gPCR & qFMRP (36/42) \\
\hline WB $(20 / 42)$ & RP-PCR/CE & & & \\
\hline $\begin{array}{l}\text { FTA } \quad \text { cards } \\
(42 / 42)\end{array}$ & AGG interruption & & & \\
\hline $\begin{array}{lr}903 & \text { protein } \\
\text { saver } & \text { cards } \\
(36 / 42) & \end{array}$ & & & & \\
\hline \multicolumn{5}{|l|}{ Buccal (42/42) } \\
\hline $\begin{array}{l}\text { Between pare } \\
\text { liquid blood, } \\
\text {-Repeat-Prime }\end{array}$ & $\begin{array}{l}\text { theses number of subje } \\
\text { TA - FTA blood spot car } \\
\text { d PCR/CE, AGG - adenin }\end{array}$ & $\begin{array}{l}s \text { or cell lines tes } \\
\text {, GS-PCR/CE - Ge } \\
\text { guanine-guanine, }\end{array}$ & $\begin{array}{l}\text { ted. Abbre } \\
\text { me-Specific } \\
\text { mPCR - me }\end{array}$ & $\begin{array}{l}\text { viations: WB - whole } \\
\text { PCR/CE, RP-PCR/CE } \\
\text { thylation PCR. }\end{array}$ \\
\hline
\end{tabular}


Table 3. Neurobehavioral Assessments of the FM-FMRP Subcohort

Domain Measure Categories

\begin{tabular}{|c|c|c|}
\hline \multirow{2}{*}{ Diagnosis } & & ASD* \\
\hline & DSM- 5 criteria & Anxiety* \\
\hline
\end{tabular}

Normal range

Intellectual Functioning $\quad$ FSIQ $\quad$ Mild ID

Moderate ID

Severe ID

\begin{tabular}{|c|c|c|}
\hline $\begin{array}{l}\text { Problem Behaviors } \\
\text { (Parent report) }\end{array}$ & $\begin{array}{rl} & 1 \\
A B C-C_{F X} & 2 \\
& 3 \\
4 \\
5 \\
6\end{array}$ & $\begin{array}{l}\text { 1. Irritability } \\
\text { 2. Lethargy/Social Withdrawal } \\
\text { 3. Stereotypic Behavior } \\
\text { 4. Hyperactivity } \\
\text { 5. Inappropriate Speech } \\
\text { 6. Social Avoidance }\end{array}$ \\
\hline \multirow{4}{*}{ Overall Clinical Severity } & \multirow{4}{*}{ CGI-S } & Severity Score Range \\
\hline & & Not at all ill (1) \\
\hline & & To \\
\hline & & Extremely ill (7) \\
\hline \multirow[t]{2}{*}{ Antipsychotic Use } & \multirow[t]{2}{*}{ Health Records } & Yes \\
\hline & & No \\
\hline
\end{tabular}

Abbreviations: DSM-5 - Diagnostic and Statistical Manual, $5^{\text {th }}$ edition; ASD - autism spectrum disorder; FSIQ - full scale intellectual quotient; Adaptive Skills, Adaptive Behavior Skills-Composite (ABS-C); $\mathrm{ABC}-\mathrm{C}_{\mathrm{FX}}$ - Aberrant Behavior Checklist-Community (fragile X version); CGI-S - clinical global impression-severity. *Subcohort also received Autism Diagnostic Observation Schedule (ADOS) assessments. **Includes social and unspecified anxiety diagnoses. A separate CGI-S scoring approach was also applied to profile for severity of social anxiety diagnosis (CGI-S $\mathrm{ANX}_{\text {). }}$.

Age distribution was comparable among individuals in the Clinical Cohort. The majority of the participants were Caucasian males (\% males/\% Caucasian): 78/76 for the entire Clinical Cohort, 84/74 for the FM-ALL Subcohort, and 84/77 for the FM-FMRP Subcohort. As shown in Table 1, the small subgroup of individuals with PM consisted of two males and three females.

\section{Materials}


The Reference Cohort consisted of three individuals in the normal FMR1 CGG range, five with PM, and three with FM, each of whom contributed a lymphoblastoid cell line. These lines were established at RUMC using standard techniques (i.e., peripheral blood mononuclear cell Epstein-Barr virus transformation). Transformed cell lines were expanded, cryopreserved, and provided as frozen stocks to the Asuragen team (Austin, TX) for further expansion. Cell lines were grown in suspension at $37^{\circ} \mathrm{C}$ in RPMI 1640 (Gibco, Thermo Fisher Scientific, Waltham, MA) supplemented with 15\% fetal bovine serum, 2 $\mathrm{mM}$ L-glutamine, and penicillin and streptomycin. Viability and total cell counts were determined using a standard trypan blue stain procedure and a phase hemacytometer (VWR, Radnor, PA); bacterial contamination was assessed using a Universal Mycoplasma Detection Kit (ATCC, Manassas, VA). After being grown to confluence $\left(\sim 8 \times 10^{5}\right.$ cells $\left./ \mathrm{mL}\right)$, cells were harvested for DNA, RNA, and total protein isolation.

\section{Whole blood collection and preservation}

Whole blood was collected using: (i) EDTA vacutainer tubes, as the whole liquid blood for initial 20 subjects, (ii) FTA cards, preserved blood saturated spot cards for all ( $N=42)$ subjects (GE Healthcare Life Sciences, Marlborough, MA), and/or (iii) 903 Specimen Collection Paper/Whatman protein saver cards for total 36/42 subjects (GE Healthcare Life Sciences). Both the whole liquid blood and FTA cards were analysed for the first 20/42 subjects. The approach demonstrated that FMR1 CGG repeat quantification and DNA methylation analysis were not affected by the method of the blood collection or storage; thus, the FTA cards were selected as a preferred sample type for the remainder 22/42 subjects of the study. FMRP analysis, however, was not supported by specimens preserved on FTA cards, which prompted use of the 903 protein saver cards as an additional specimen collection. Cards were spotted with $\sim 125 \mu \mathrm{L}$ of whole blood (EDTA tubes) and stored at room temperature. Specimens from each subject were shipped to Asuragen for subsequent molecular and protein testing (FMR1 and FMRP analysis).

\section{Matched blood and buccal specimens}

Matched whole blood and buccal cell specimens were collected from 42 patients from the Clinical Cohort. Buccal cell samples were collected using ORAcollect-DNA (DNA Genotek, OCR-100) following the manufacturer's instructions, while blood samples were obtained using standard clinical procedures, both following informed consent and according to protocols approved by the Johns Hopkins Medicine's IRB.

\section{Genomic DNA and protein isolation and primary characterization}

Genomic DNA was isolated from the whole blood specimens (Clinical Cohort, $N=42$ ) and cell lines described above using the DNeasy Blood and Tissue Kit (Qiagen, Germantown, MD) according to the manufacturer's instructions. The concentration of gDNA was determined using spectrophotometry (NanoDrop, Thermo Fisher Scientific). The level of intact or non-fragmented DNA was assessed by agarose gel electrophoresis (AGE, E-Gels Precast Agarose Gels; Thermo Fisher Scientific, Waltham, MA). 
To isolate multiple analytes (DNA, RNA) simultaneously from the cell lines, we used the AllPrep DNA/RNA Mini Kit (Qiagen, Germantown, MD) following the manufacturer's instructions. Nucleic acid concentration was determined by spectrophotometry (NanoDrop, Thermo Fisher Scientific). Additionally, RNA integrity was determined on the 2100 Bioanalyzer (Agilent, Santa Clara, CA) using standard procedures. The minimum RNA Integrity Number (RIN) for all samples was 9.6.

Total protein was isolated using Cell Extraction Buffer (CEB, Thermo Fisher Scientific, Waltham, MA) according to the manufacturer's instructions. Briefly, cell pellets were washed by re-suspension in ice-cold phosphate-buffered saline (PBS) followed by centrifugation at $300 \mathrm{xg}$ for 7 minutes at $4^{\circ} \mathrm{C}$. After aspirating the PBS, cells were lysed using $1 \mathrm{~mL} C E B / 10^{8}$ cells and incubated on ice for 30 minutes with occasional vortexing followed by centrifugation at $300 \mathrm{xg}$ for 7 minutes at $4^{\circ} \mathrm{C}$ to collect cell debris. Total protein concentration of the lysates was determined using a Pierce BCA Protein Assay Kit (Thermo Fisher Scientific, Waltham, MA).

\section{Molecular assessments}

\section{CGG repeat genotyping and $A G G$ interruption analysis}

FMR1 genotypes from cell-line and blood sample gDNA were determined using triplet repeat-primed PCR, followed by fragment analysis of amplicons by capillary electrophoresis (CE) on an ABI 3500xI Genetic Analyzer (Thermo Fisher Scientific, Waltham, MA), and Sanger sequencing. PCR-based CGG repeat genotyping was performed with both two-primer and three-primer FMR1 PCR/CE [FMR1 gene-specific PCR/CE (GS-PCR/CE) and repeat-primed PCR/CE (RP-PCR/CE), AmplideX ${ }^{\circledR}$ PCR/CE FMR1 Kit (Asuragen, Austin, TX)] [20, 21]. Cell-line gDNA samples were also analysed using two-primer FMR1 PCR with products resolved by AGE (GS-PCR/AGE) [21]; this permitted sizing of repeat expansions larger than 200 CGG that cannot be sized within the resolution limits of CE. Samples were annotated as size mosaics if they manifested peaks in two different size categories such as PM and FM with a peak signal intensity greater than 75 relative fluorescence units (RFU) by CE. The number and sequence context of interrupting AGG sequences in the repeat tract was determined using Xpansion Interpreter ${ }^{\circledR}$, a PCR-based method (Asuragen, Austin, TX) [40, 41, 45, 48].

\section{Methylation PCR analysis}

The AmplideX mPCR FMR1 Kit (Asuragen, Austin, TX) was used to quantify relative allele-specific DNA methylation of the FMR1 gene $[39,49]$ on gDNA from blood and buccal samples or cell lines. Both Xinactivation and methylation of the expanded allele could be assessed using this method, revealing completely or partially methylated states [44]. A sample was defined as a methylation mosaic (MM) if it contained FM or PM fragment peak(s) above 75 RFU by CE that was/were $<80 \%$ methylated in at least one sample type (buccal swab or whole blood).

Southern blot analysis 
Southern blot analysis was performed utilizing gDNA isolated either from the whole blood samples or from the cell lines. DNA was digested with EcoRI and Nrul and separated on an agarose gel. After DNA transfer, the membranes were hybridized with the FMR1-specific StB12.3 genomic probe, and imaged according to published procedures [50].

\section{FMR1 mRNA analysis}

FMR1 transcript expression was evaluated via quantitative real-time PCR (qPCR) for all cell lines samples. A total of 2.5 ug of purified total mRNA was converted to CDNA using a reverse transcription (RT) protocol. The RT reaction was incubated at $42^{\circ} \mathrm{C}$ for 45 minutes followed by 10 minutes at $93^{\circ} \mathrm{C}$, and then rapidly cooled to $4^{\circ} \mathrm{C}$. FMR1 mRNA specific primers (Integrated DNA Technologies, Coralville, IA) [Forward Primer: 5'- TATGCAGCATGTGATGCAACT-3', Reverse Primer: 5'- TTGTGGCAGGTTTGTTGGGAT-3'] for use with the/a KAPA SYBR Fast qPCR kit (KAPA Biosystems, Wilmington, MA) were applied according to the manufacturer's instructions. Each sample was run at two input concentrations of $31 \mathrm{ng} / \mathrm{ul}$ and 6.25 $\mathrm{ng} / \mathrm{ul}$, respectively. FMR1 mRNA expression was quantified relative to expression of the control housekeeping gene USP33 [42].

\section{Quantitative FMRP analysis}

FMRP levels were determined using a quantitative FMRP (qFMRP) assay developed by Lafauci et al [43], per the method described by Gustin et al. [42]. This assay utilizes a recombinant FMRP peptide (GST-SR7) as a standard for quantification of FMRP level. Protein (on 903 paper) and gDNA were co-extracted from $3 \mathrm{~mm}$ dried blood spot punches. DNA was quantified using the PicoGreen Quant-iT ${ }^{\mathrm{TM}}$ HS kit (Thermo Fisher Scientific, Waltham, MA). The amount of FMRP was normalized to the amount of gDNA, as a proxy for cell count, to reduce the variability among samples.

\section{Clinical assessments}

Table 3 summarizes the neurobehavioral assessments carried out on the FM-FMRP cohort $(N=31)$. They included: (i) presence (diagnosis) of ASD, social anxiety (SA), and/or unspecified anxiety, (ii) level of intellectual functioning/intellectual disability (ID), as determined by Full Scale Intelligence Quotient (FSIQ), (iii) level of adaptive functioning, (iv) severity of problem behaviors, (v) overall clinical severity, as determined by the Clinical Global Impression-Severity scale (CGI-S), and (vi) use of antipsychotics.

The following assessment tools were employed:

(i) Diagnostic and Statistical Manual-5th Edition criteria (DSM-5) [51], supplemented by available Autism Diagnostic Observation Schedule (ADOS) assessments, were used to diagnose ASD. Diagnosis of ASD was performed longitudinally for the Clinical Cohort by a clinician (DBB) with experience in idiopathic ASD and ASD in FXS [26]. Diagnoses of SA and unspecified anxiety were also performed using DSM-5 criteria [27, 32]. SA include a substantial social inhibition (shyness) accompanied by a broad range of fear of negative evaluation by others, which may be embarrassing, lead to rejection or offend others such as the expression of anger toward others. "Fragile-X handshake" and various forms of "escape" behaviors 
in familiar or especially unfamiliar situations are common as well. [See section (v) for profiling of severity/level of SA diagnosis].

(ii) FSIQ was determined by the Stanford-Binet Intelligence Scales-5th Edition (SB-5) for 15/31 individuals, the Wechsler Preschool and Primary Scale of Intelligence (WPPSI) for 1/31, the Wechsler Intelligence Scale for Children (Fourth and Fifth Edition, WISC-IV and WISC-V) for 7/31, The Differential Ability Scales (DAS) for 4/31 and the Mullen Scales of Early Learning for 4/31 [38]. To address the skewed effect of FSIQ-standard or other score testing, raw-score based z-score calculations from the IQ subtests were used by a senior neuropsychologist (EMM) to generate extended FSIQ values [53]. When there were several administrations of a test, the most current one was used for data analysis.

Alternatively, if the scores were highly discrepant, estimation was made via interpolation of the two scores.

To determine level of ID, the extended FSIQ scores were also used instead of adaptive skill scores because the former, as scaled measures, better reflect the range of cognitive abilities. Subjects were assigned to one of four ID levels: normal range (FSIQ score $\geq 70$ ), mild ID (FSIQ: 55-69), moderate (FSIQ: 35-54) and severe ID (FSIQ <35).

(iii) Adaptive functioning was assessed by using adaptive skill scales, which included the Vineland Adaptive Behavior Scales-Second Edition (VABS-II) for most participants, the Adaptive Behavior Assessment System Second and Third Editions (ABAS-2 and 3) for 10 individuals, and Scales of Independent Behavior-Revised (SIB-R) for 2 participants.

(iv) Problem behaviors were assessed by the Aberrant Behavior Checklist-Community Edition (ABC-C) adapted for FXS (ABC- $C_{F X}$ ), which applies a subscale scoring algorithm developed specifically for the disorder and yields six subscales [52]: (i) Irritability, (ii) Lethargy/Social Withdrawal, (iii) Stereotypic Behavior, (iv) Hyperactivity, (v) Inappropriate Speech, and (vi) Social Avoidance [52, 54]. The ABC- $\mathrm{C}_{\mathrm{FX}}$ has been applied as a primary outcome measure in multiple observational and interventional studies in FXS (reviewed in [38]).

(v) The CGI-S score evaluates the overall impairment of a patient, using as reference the clinician's past experience with patients who have the same diagnosis. Possible ratings of the CGI-S are: 1-normal, not at all ill, 2-borderline ill, 3-mildly ill, 4-moderately ill, 5-markedly ill, 6-severely ill, and 7- extremely ill. The CGI approach was also separately applied to profile the severity/level of SA (CGI-S $\mathrm{ANX}_{\text {X }}$; based on CGI-S $\mathrm{SNX}_{\text {ANX }}$ scores, two categories were defined: $\geq 5$ (severe) and $\leq 4$ (mild-moderate).

(vi) A patient's use of antipsychotics was determined through health records and marked as 'there is' or 'there is not' (yes/no) use of this class of drugs.

\section{Statistical analysis}


Statistical analysis was performed using IBM SPSS Statistics version 25 (IBM Corporation, Armonk, NY) or JMP version 14 (SAS Institute, Cary, NC). Descriptive statistics included frequency (percent) of nominal variables, and median, mean, standard deviation (SD), and range for continuous variables. Tests of normality and homogeneity of variances were also performed. Depending on data distribution, either parametric or non-parametric tests were applied. The Chi square test was used to test differences between nominal variables (frequencies). Pearson's correlation coefficient was used as a measurement of the strength of the linear relationship between normally distributed variables. Welch's t-test for unequal variances and equivalent non-parametric tests (Mann-Whitney) were performed to compare means of two samples. Welch's $t$-test maintains type I error rates close to nominal for unequal variances and for unequal sample sizes under normality. Significance was indicated by $p £ 0.05$ and high significance by $p$ $£ 0.01$.

\section{Results}

FMR1 DNA, RNA, and protein assays assessed in a reference cell-line cohort

High-resolution, sensitive, and specific analyses of the gene and its protein are necessary to understand genotype-phenotype links and their potential clinical impact for FXS. We first compared nine FMR1 DNA, RNA, or protein-based assays (Table 2) using 11 well-characterized lymphoblastoid cell lines (Table 4) from patients with FXS. These nine assays included five FMR1 DNA assays [20, 39-41, 48] (Fig. 1). As shown in Fig. 1A and 1B, the results from both GS-PCR/AGE and RP-PCR/CE were in agreement, both for genotype category (i.e., normal, PM, or FM) and number of CGG repeats (within the known sizing resolution of AGE and CE). Sanger sequencing of selected expanded samples (Fig. 1: RU06 and RU08) confirmed the findings. Analysis of interrupting AGG elements were consistent with previous reports demonstrating that these interspersions were more highly represented in unexpanded alleles $[40,55]$. 
Table 4 Genetic and clinical characteristics of 11 subjects who provided blood cells for immortalized lymphoblastoid cell lines used in this study 


\begin{tabular}{|c|c|c|c|c|}
\hline \multirow[t]{5}{*}{ ID } & \multirow[t]{5}{*}{ Gender } & CGG & \multirow[t]{5}{*}{ Clinical Annotation } & CGG \\
\hline & & Repeat & & Repeat \\
\hline & & Genotype* & & Genotype** \\
\hline & & Whole & & Cell line \\
\hline & & Blood & & \\
\hline RU001 & M & 20 & Clinically normal & 20 \\
\hline RU002 & $\mathrm{F}$ & $30 / 30$ & Clinically normal & $30 / 30$ \\
\hline \multirow[t]{2}{*}{ RU003 } & M & $>200$ & FXS and moderate intellectual impairment, & $>200$ \\
\hline & & $(\sim 900)$ & fully methylated FM & \\
\hline \multirow[t]{2}{*}{ RU004 } & M & 78 & Clinically unaffected, Grandchild with FXS, & 85 \\
\hline & & & unmethylated PM allele & \\
\hline \multirow[t]{5}{*}{ RU005 } & $\mathrm{F}$ & 23/118, & Chronic fatigue syndrome, & 23/113, \\
\hline & & $\begin{array}{l}\text { 124-169, } \\
\text { minor }\end{array}$ & Daughter with FXS, & 118 \\
\hline & & $>200$ & with low-level mosaicism for a FM allele of $>200$ repeats. & FM not \\
\hline & & & Both methylated and unmethylated expanded alleles & present \\
\hline & & & apparent by Southern blot analysis. & \\
\hline \multirow[t]{3}{*}{ RU006 } & M & 62 & Clinically unaffected & 64 \\
\hline & & & Grandson with FXS & 41,51 \\
\hline & & & umethylated PM & \\
\hline \multirow[t]{6}{*}{ RU007 } & $\mathrm{F}$ & $18 / 116$ & Mild tremor, & $18 / 115$ \\
\hline & & & Son with FXS & \\
\hline & & & PM allele with repeat length of 115 with low-level mosaicism & \\
\hline & & & and a FM allele of $>200$ repeats. & \\
\hline & & & Both methylated and unmethylated expanded alleles & \\
\hline & & & apparent by Southern blot analysis. & \\
\hline
\end{tabular}




$\begin{array}{lll}\text { RU008 M } & \sim 180 & \text { Male with normal development but mild symptoms of FXTAS }>200,86 \\ & \text { mosaicism } & \text { and grandchildren with FXS, donor subject has alleles with } \\ \text { and }>200 & \text { unmethylated CGG repeat lengths of about } 180 \text { and }>200 \text { by } \\ & \text { Southern blot analysis. }\end{array}$

\begin{tabular}{lllll}
\hline RU009 & F & $30 / 32$ & Clinically normal & $30 / 32$ \\
\hline RU010 & F & $30 />200$ & Female with FXS and mild ID, a fully methylated FM allele & $30 />200$ \\
& & with CGG repeat length of $\sim 600$ & \\
\hline
\end{tabular}

$\begin{array}{llll}\text { RU011 F } & \text { 30/56 } \quad \text { Clinically unaffected relatives with FXS }\end{array}$

*Genotype determined using FMR1-specific repeat-primed PCR RP-PCR or a combination of RP-PCR and Southern blot analysis

**Genotype determined from cell lines with RP-PCR assay

FXTAS - fragile X-associated tremor ataxia syndrome

Next, FMR1 mPCR was used to determine the extent of gene methylation and silencing. As expected, the normal and PM cell-lines were unmethylated (males) or partially methylated (females). Two of the three FM cell lines were nearly completely methylated consistent with inactivation of FMR1 in FXS. However, one FM cell-line (RU08) was unmethylated (Fig. 1C). Southern blot analysis of the original whole blood sample also showed lack of methylation (Table 4). To investigate this finding further, we isolated RNA and quantified the primary FMR1 mRNA isoform on all 11 cell lines. Since a lack of FMR1 methylation would be expected to be associated with transcription of the gene, we anticipated that FMR1 RT-qPCR would demonstrate substantially greater transcript levels for RU08 compared to the other two FM celllines with methylated FMR1. Indeed, this was the case (Fig. 1D). The level of FMR1 expression was also consistent with methylation status for the other cell-line samples (Fig. 1D).

Finally, we measured FMRP levels for each cell-line to assess the impact of repeat expansions and other FMR1 DNA and RNA parameters on translation. Lysates of the 11 cell lines were analysed by a previously established antibody-based qFMRP liquid bead array assay $[42,43]$. As shown in Fig. 1E, FMRP levels were found to be well above baseline for nine of the 11 cell lines including the unmethylated FM cell line (RU08). The two FM samples (RU09 and RU10) with pronounced gene methylation showed absence of FMRP. Thus, the results indicate that this set of multianalyte assays can quantify FMR1 gene and FMRP parameters across the range of FMR1 categorical genotypes with complementary results. 


\section{DNA and protein analysis of a cohort of patients with FMR1 triplet repeat expansions}

Having shown the linkage between FMR1 nucleic acid and protein assays in cell lines immortalized from patients with detailed clinical annotations, we then selected a random group of patients with expanded FMR1 genotypes that had been assessed through the KKI's Fragile X Program (Clinical Cohort, Table 1). The FM FMRP Subcohort of the Clinical Cohort was further divided into those with FXS-only and those with FXS + ASD. Additional information on the demographics of this cohort are provided in the Methods section and in Table 1. Whole blood (preserved on FTA cards) and buccal samples (preserved in a stabilizing solution), collected from each subject for subsequent molecular and protein testing, allowed comparisons of FMR1 and FMRP profiles on cells from different lineages.

Using both GS-PCR/CE and RP-PCR/CE, we found that the genotype categories determined for the overall Clinical Cohort were consistent with the original diagnostic test in each case. Specifically, the five PM samples had 56-113 repeats, whereas all 37 FM samples had alleles $>200$ repeats (Fig. 2A and Fig. 2B). Further, the number of CGG repeats was almost always conserved when comparing DNA from whole blood collected in EDTA tubes, whole blood collected on FTA cards, or preserved buccal cells. The differences observed were generally restricted to the appearance of low-level size mosaic peaks (Figs. 3 and 4). Overall, slightly more than half of the samples were FM mosaics with evidence of PM alleles. This proportion is roughly in line with previous studies indicating that $40 \%$ of FM samples are allele size mosaics $[12,56]$. PCR assays that mapped AGG elements in the repeat tract revealed no difference in the interruption pattern when comparing blood and buccal DNA for either unexpanded (most of which had AGG interspersions) or expanded alleles (many of which did not have AGGs).

As expected, the MPCR results indicated partially methylated or unmethylated PM alleles. For example, all three female PM samples were partially methylated and both male PM samples were unmethylated. Further, fully methylated FM alleles were observed in specimens from most subjects with FXS. Indeed, greater than $90 \%$ allele-specific methylation was observed for at least one discernible FM peak or near-FM peak in the $\mathrm{CE}$ trace for all $37 \mathrm{FM}$ samples. Most samples revealed multiple peaks in the sizeable range of $\mathrm{CE}$; $\mathrm{MM}$ was also commonly observed when considering all peaks in a sample, including those with relatively low signal intensity (Figs. $3 \mathrm{C}$ and 4). Of note, the average methylation of the normal $\mathrm{X}$ allele in the six females with FM was $44 \%$, consistent with previous reports $[39,47,52]$ and lyonization, as well as the expectation of a less severe clinical phenotype compared to the 26 males.

As a next step, we assessed qFMRP levels across the subjects in the entire Clinical Cohort (Fig. 2C). Group analysis of PM compared to FM demonstrated that qFMRP levels were higher in the former; however, three out of five PM were females, which generally have higher qFMRP levels compared to males. In addition, this analysis was limited by having only five individuals with PM. qFMRP levels within the FM-FMRP Subcohort spanned a 30-fold range, when both genders were included $(N=31)$, and a 12fold range when only the male subset was analysed $(N=26)$. Since epigenetic mosaicism may indicate subpopulations of cells that are competent to express FMRP, the FM male subset was further analysed by comparing FMRP levels from subgroups with either appreciable $M M(N=13)$ or no measurable $M M(N=$ 
13) [Additional file 1]. Of note, the MM subgroup included those with appreciable size mosaicism and MM (as defined in the Methods) but was categorized as MM given the more direct linkage between methylation status and FMR1 expression. ANOVA demonstrated that FMRP expression was significantly higher in samples with MM compared to those without MM $(p=0.02)$ (Fig. 5).

\section{Blood and buccal samples analyses: Molecular comparisons within the overall Clinical Cohort}

Heterogeneity in FMR1 repeat size and methylation occurs in many patients with pathogenic repeat expansions. Nonetheless, it can also manifest in different tissues from the same patient, though the potential phenotypic consequences of these differences are not well understood. Consequently, we compared FM DNA profiles across matched blood and buccal specimens from the same individual. Mosaicism, as we defined it, was (i) detected with high analytical sensitivity using assays previously known to report mosaicism down to $1-5 \%$ of cell equivalents $[21,57,58]$, and (ii) detected in about $50 \%$ of the subjects in our cohort [Additional file 1]. As a result, this study offered multiple individuals for comparisons of matched blood and buccal specimens. In general, we found that mosaicism was conserved between these specimens from the same patient. Yet, there were a handful of notable exceptions. One example is a 101-104 CGG size mosaic in sample 04 that was nearly completely unmethylated in DNA isolated from EDTA tubes or from the corresponding spotted blood cards but $49 \%$ methylated in the buccal DNA (Fig. 4A). Another example (sample 15) showed mosaic peaks corresponding to 121 and 162 CGG repeats in blood that were absent in the buccal sample (Fig. 4C). When differences in mosaicism were observed, however, they were largely constrained to allele-specific methylation in lower-intensity amplicon peaks by $\mathrm{CE}$; repeat length and even peak intensity of size mosaics was conserved in nearly all samples. Thus, a general finding from our study was that the primary genotype and epitype was maintained in matched blood and buccal specimens.

\section{Neurobehavioral profile of the FM-FMRP Subcohort}

Table 5 depicts the neurobehavioral profiles of individuals in the FM-FMRP Subcohort $(N=31)$. Their age distribution was comparable to the FM-ALL Subcohort $(\mathrm{N}=37)$. Although the number of male and female subjects was not balanced, gender differences in cognitive and adaptive measures, as well as distribution of intellectual functioning, were in line with the literature [35]. Mean FSIQ and adaptive skills composite scores were significantly lower in males than in females $(p=0.016$ and $p=0.001$, respectively, MannWhitney) and all individuals with moderate or severe ID were males. Frequency of SA diagnosis was high for both genders $(68 \%)$, especially for females $(100 \%)$. Unspecified anxiety was only found in males (38\%), particularly among the lowest functioning (data not shown). Not surprisingly, ASD was present more frequently in males with FXS ( $46 \%$ vs. $20 \%$ females), who also had statistically significantly higher mean ABC- $C_{F X}$ total and CGI-S scores than females $(p=0.005$ and $p=0.036$, respectively, MannWhitney). FMRP levels were also significantly lower in males than females ( $p=0.005$, Mann-Whitney). 
Table 5. Neurobehavioral profiles by gender in the FM-FMRP Subcohort

ariable ge years, mean (SD)

SIQ, mean (SD)

daptive Skills Composite, mean (SD)

Itellectual functioning ${ }^{¥}, \mathrm{~N}$

Normal range IQ, $\mathrm{N}(\%$ of $\mathrm{N})$

Mild ID, $\mathrm{N}(\%$ of $\mathrm{N})$

Moderate ID, $\mathrm{N}(\%$ of $\mathrm{N})$

Severe ID $(\%$ of $N)$

GI-S (overall), mean (SD)

nxiety, total $\mathrm{N}$

Social Anxiety, N (\% of N)

Unspecified anxiety, $\mathrm{N}(\%$ of $\mathrm{N})$

SD, N (\%)
FM-FMRP

Subcohort

males females $N=31$ Square

$\mathrm{N}=\quad \mathrm{N}=5$

26

31

(11.9)

$31 \quad 43.6$

(18.3)

$31 \quad 60.8$

(12.0)

31

$31(4)$

$7 \quad 4(16)$

(40)

(13.2)

74.8

1.36

(19.1)

(df)/

†Chi-

(df)
$\S \mathrm{F} \quad P$ 
BC- $\mathrm{C}_{\mathrm{FX}}$, mean (SD)

ntipsychotics, $\mathrm{N}$ (\% of $\mathrm{N}$ )

MRP, mean pg/ng (SD)
59 (19.6)

(12.6)
$28.7 \quad 14.0(1)^{\S} \quad 0.005^{*}$
$10(38)$

$4.2(3.3)$
$0(0) \quad 0.8(1)^{\dagger}$

$14.3 \quad 19.7(1)^{\S}$

$0.005^{*}$

(9.5)

\begin{abstract}
Abbreviations: FM - full mutation, ASD - autism spectrum disorder, FSIQ - full scale intelligence quotient, raw-score based z-score calculations from the IQ subtests as the basis for an extended FSIQ values, IQ - intelligence quotient, ID - intellectual disability, CGI-S - Clinical Global Impression-Severity, $\mathrm{ABC}-\mathrm{C}_{\mathrm{FX}}$ - Aberrant Behavior ChecklistCommunity (fragile $\mathrm{X}$ version), FMRP - fragile $\mathrm{X}$ mental retardation protein, $\mathrm{N}$ - number of participants, SD - standard deviation, $\S \mathrm{F}$ - statistic ratio for one-way ANOVA, df - degrees of freedom. † Chi-Square test was used, *statistically significant continuous data, MannWhitney, $\dagger *$ Chi-Square statistically significant $¥$ Chi-Square Intellectual functioning: normal range IQ (FSIQ score >70); mild ID (FSIQ: 55-69), and moderate (FSIQ: 35-54) and severe ID (FSIQ <35).
\end{abstract}

\title{
Neurobehavioral profile of individuals with ASD in the FM-FMRP Subcohort
}

In order to determine the influence of ASD status on neurobehavioral profiles in the FM-FMRP Subcohort, we compared males with and without ASD (FXS + ASD and FXS-only). Table 6 depicts these neurobehavioral profiles. Analogous to the differences between males and females, males with ASD had lower level of intellectual functioning, higher proportion of unspecified anxiety diagnosis, and higher mean $\mathrm{ABC}-\mathrm{C}_{\mathrm{FX}}$ total and CGI-S scores than females. FMRP levels were also significantly lower in the FXS + ASD than in the FXS-only group. As expected from the literature, the FXS + ASD group also had higher scores on the $A B C-C_{F X}$ Irritability and Stereotypy subscales and a more prevalent use of antipsychotics. As mentioned above, SA was less prevalent in males FXS + ASD. However, SA severity using a CGI-S adapted measure (CGI-S ${ }_{\text {ANX }}$ ) revealed a closer relationship between SA and ASD. When individuals with mild-moderate $\mathrm{CGI}-\mathrm{S}_{\mathrm{ANX}}$ scores $(\leq 4, \mathrm{~N}=7)$ were compared with those with severe CGI-S ${ }_{\mathrm{ANX}}$ scores $\left({ }^{3} 5, \mathrm{~N}\right.$ $=9)$, the proportion of males with ASD was higher in the latter (1/7 versus $4 / 9$, respectively). Again, similar to the comparisons between males and females, males with FXS + ASD had lower levels of FMRP than those with FXS-only (Table 6, Fig. 6). 
le 6. Neurobehavioral profiles by ASD status in males in the FM-FMRP Subcohort 


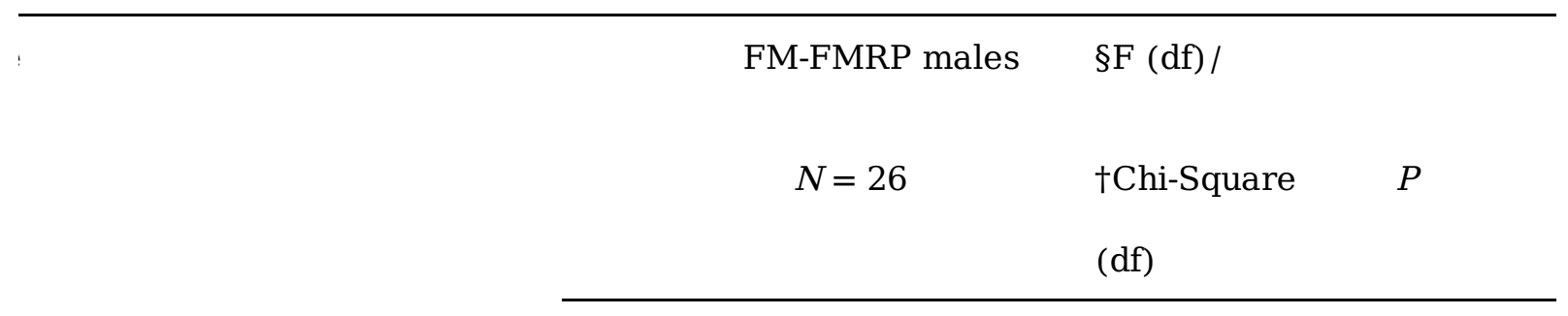

\begin{tabular}{|c|c|c|c|c|c|}
\hline & \multirow{4}{*}{$\mathrm{N}$} & \multirow{4}{*}{\multicolumn{2}{|c|}{$\begin{array}{cl}\text { FXS-only } & \text { FXS }+ \\
\mathrm{N}=14 & \text { ASD } \\
& \mathrm{N}=12\end{array}$}} & \\
\hline & & & & & \\
\hline & & & & & \\
\hline & & & & & \\
\hline \multirow[t]{2}{*}{ rs, mean (SD) } & 26 & 17.1 & $9.9(4.9)$ & $2.5(1)^{\S}$ & 0.13 \\
\hline & & $(15.1)$ & & & \\
\hline in (SD) & 26 & 49.8 & 36.4 & $3.6(1)^{\S}$ & $0.03^{*}$ \\
\hline \multirow[t]{3}{*}{ ¡kills Composite, mean } & 26 & $(17.5)$ & $(17.0)$ & $1.8(1)^{\S}$ & 0.17 \\
\hline & & 62.3 & 58.2 & & \\
\hline & & $(13.9)$ & $(10.5)$ & & \\
\hline ll functioning ${ }^{¥}, \mathrm{~N}$ & 26 & & & & \\
\hline mal range IQ, $\mathrm{N}$ (\% of & 1 & $1(7)^{\#}$ & $0(0)$ & $5.3(1)^{\dagger}$ & $0.02^{\dagger_{*}}$ \\
\hline I ID, N (\% of $\mathrm{N})$ & 4 & $3(21)$ & $1(8)$ & $5.8(1)^{\dagger}$ & $0.01^{\dagger} *$ \\
\hline lerate ID, $\mathrm{N}(\%$ of $\mathrm{N})$ & 11 & $7(50)$ & $4(33)$ & $5.3(1)^{\dagger}$ & $0.02^{\dagger *}$ \\
\hline əre ID, $\mathrm{N}(\%$ of $\mathrm{N}$ ) & 10 & $3(21)$ & $7(58)$ & $27.1(1)^{\dagger}$ & $<0.0001^{\dagger} *$ \\
\hline \multirow[t]{2}{*}{ ərall), mean (SD) } & 26 & $4.6(0.9)$ & $5.9(0.7)$ & $6.6(1)^{\S}$ & $0.03^{\dagger *}$ \\
\hline & 26 & & & & \\
\hline ial Anxiety, N (\%) & 16 & $11(79)$ & $5(42)$ & $7.9(1)^{\dagger}$ & $0.05^{\dagger *}$ \\
\hline pecified Anxiety, N (\%) & 10 & $3(21)$ & $7(58)$ & $7.9(1)^{\dagger}$ & $0.05^{\dagger *}$ \\
\hline \multirow[t]{2}{*}{ mean (SD) } & 26 & 51.7 & 67.4 & $4.8(1)^{\S}$ & $0.04^{*}$ \\
\hline & & $(17.0)$ & $(19.7)$ & & \\
\hline : Irritability & 26 & $\begin{array}{l}17.2 \\
(9.2)\end{array}$ & $26(11.7)$ & $4.6(1)^{\S}$ & $0.04 *$ \\
\hline : Unresponsive & 26 & $6.8(4.6)$ & $8.7(3.7)$ & $1.4(1)^{\S}$ & 0.2 \\
\hline
\end{tabular}




\begin{tabular}{lc|cccc} 
: Stereotypy & 26 & $6.6(3.8)$ & $10.2(4.7)$ & $4.6(1)^{\S}$ & $0.04^{*}$ \\
: Hyperactivity & 26 & 15.4 & $18.8(8.1)$ & $1.1(1)^{\S}$ & 0.3 \\
& & $(8.6)$ & & & \\
; Inappropriate Speech & 26 & $4.8(3.3)$ & $5.8(3.7)$ & $0.6(1)^{\S}$ & 0.4 \\
: Social Avoid & 26 & $3.9(3.0)$ & $4.0(2.6)$ & $0.02(1)^{\S}$ & 0.9 \\
Jtics, N (\%) & 26 & $3(21)$ & $7(58)$ & $3.7(1)^{\dagger}$ & $0.05^{\dagger}$ \\
/ng], mean (SD) & 26 & $5.4(4.0)$ & $2.8(1.3)$ & $4.6(1)^{\S}$ & $0.04^{*}$ \\
\hline
\end{tabular}

sreviations: FM - full mutation, FXS - fragile X syndrome, ASD - autism spectrum order, FSIQ - full scale intelligence quotient, Extended raw-score based scoring of the Q, ID - intellectual disability, CGI-S - Clinical Global Impression-Severity, ABC-CFX srrant Behavior Checklist-Community (fragile X version), FMRP - fragile X mental ardation protein, $\mathrm{N}$ - number of participants, SD - standard deviation, $\mathrm{F}$ - statistic o for one-way ANOVA, df - degrees of freedom. + Chi-Square test, *statistically aificant continuous data, Welch's t-test, ${ }^{\dagger} *$ Chi-Square statistically significant; itellectual functioning: normal (FSIQ score >70); mild ID (FSIQ: 55-69), moderate IQ: $35-54$ ) and severe ID (FSIQ <35).

\section{Intellectual functioning, ASD status, and FMRP levels}

Analyses of the FM-FMRP Subcohort presented above have demonstrated by groups with lower cognitive functioning, as well as those with ASD, have lower FMRP levels. Thus, we evaluated in greater detail the relationship between intellectual functioning and ASD, and related behaviors, and FMRP in the male subgroups described in Table 6. First, we examined the distribution of FMRP values in those with or without ASD. There were four outliers in the FXS-only; when either two randomly selected or the four were excluded from the analyses, both parametric and nonparametric t-tests showed significant lower levels in the FXS + ASD group ( $p=0.05$ and $p=0.01$, respectively; Welch's t-test and Mann-Whitney).

Since previous studies have already reported an inverse relationship between intellectual functioning and FMRP levels and a close association between more severe ID and ASD, we also evaluated the role of level of intellectual impairment in the ASD-lower FMRP relationship. An assessment of ID categories and FMRP levels showed that males with FXS and either mild or moderate ID had significantly higher levels of FMRP than those with severe ID $(N=15,5.2 \pm 3.8$ versus $N=10,2.3 \pm 1.1 ; p=0.013$ and $p=0.019$, respectively; Welch's t-test and Mann-Whitney). These differences were also present when males with FXS + ASD and mild or moderate ID were compared with those with ASD and severe ID ( $N=5,3.3 \pm 1.4$ versus $N=7,2.4 \pm 1.2)$ affected by the small subsample ( $p=0.4$, Mann-Whitney), and when similar groups without ASD were compared (FXS-only and mild + moderate ID versus FXS-only and severe ID: N = 10, 6.1 
\pm 4.3 versus $\mathrm{N}=3,2.1 \pm 0.6, \mathrm{p}=0.015$ and $\mathrm{p}=0.07$, respectively; Welch's t-test and Mann-Whitney). There was also a statistical trend towards lower FMRP levels in the FXS + ASD subgroup with mild + moderate ID when compared with FXS-only with mild + moderate ID $(N=5,3.3 \pm 1.4$ versus $N=10,6.1 \pm 4.3 ; p=$ 0.075 , Welch's t-test), but no differences when groups with severe ID with and without ASD were compared. Another factor that could contribute to the ASD-lower FMRP association is the presence of social behaviour impairment that can be interpreted as or associated with ASD. As described above, the group of males with severe SA, by CGI-S $\mathrm{ANX}_{\text {s }}$ scores, had a higher proportion of individuals with ASD. This group also had lower FMRP levels than those with mild-moderate SA ( $3.1 \pm 2.2$ versus $5.4 \pm 3.4 ; p=0.05$, Mann-Whitney).

Finally, we examined the influence of age, overall clinical severity, as measured by CGI-S, and overall problem behaviour severity, as determined by $A B C-C_{F X}$ total score, on FMRP levels within the FXS + ASD group. Younger individuals (2-11 years) had lower FMRP levels at a trend level ( $p=0.07$, Welch's t-test); while males with an $A B C-C_{F X}$ total score $\geq 50$ and/or severe CGI-S scores $(\geq 5)$ had significantly lower mean levels of FMRP $(p=0.01$ and $p=0.05$, respectively; Welch's t-test).

To illustrate the potential clinical impact of the FMR1 and FMRP measurements reported here, one high functioning 7-year old male in the FXS-only group was an outlier with a normal FSIQ of 95 and an adaptive VABS-II Composite score of 79. His FMRP level was 7.4; (mean \pm SD) all males (4.2 \pm 3.3 ), FXSonly (5.4 \pm 4.0$)$. The subject had unmethylated size and methylation mosaicism on his blood sample, and a partially methylated PM smear with an additional PM peak on the buccal sample.

\section{Discussion}

To our knowledge, this is the first study to integrate high-resolution FMR1 DNA, RNA and protein analyses and to correlate these molecular measures with multiple neurobehavioral parameters, in order to refine genotype-phenotype correlations in FXS. We first used multiple FMR1 and FMRP assays to deeply profile pathogenic FMR1 CGG expansions, and to determine their impact on transcription and translation in wellcharacterized cell lines from individuals with a range of FMR1 genotypes. We then applied the most revealing of these assays to a FXS cohort with comprehensive neurobehavioral profiling to investigate molecular profiles and molecular-neurobehavioral correlations.

Using a combination of sensitive and quantitative multi-omic assays we found that FMR1 CGG repeat length, methylation levels, and FMRP levels were complementary and consistent with our current knowledge of FMR1 translational biology in individuals with normal, PM, and FM alleles $[1,2,4,5]$. Molecular profiles in lymphoblastoid cell lines were corroborated in blood samples with a variety of FMR1 expansions, and blood-based profiles were in general consistent with those in buccal epithelial specimens. These findings are contributory since concordance in patterns of FMR1 mosaicism across tissues continues to be a controversial issue in $\operatorname{FXS}[46,59,60]$. A representative sample of males and females with FXS, with their corresponding range of cognitive and behavioral impairments $[9,29]$, served as the basis for examining FMR1 methylation, FMRP levels and their relationship with neurobehavioral 
features. As expected, samples with complete or near complete FMR1 gene methylation by MPCR exhibited the lowest FMRP values. Females with FXS, not surprisingly, showed lower relative gene methylation and higher FMRP levels. FMRP levels were generally lower for males with FM-only compared to males with $\mathrm{PM}$, females with $\mathrm{FM}$, and males with methylation mosaicism, with the latter groups displaying a wide range of values as described earlier $[9,10,19]$. A significant finding from this study is that FMRP levels were two-fold higher in males with FXS and appreciable methylation mosaicism, expanding our knowledge on the link between methylation and FMR1 silencing. Jiraanont and colleagues used FMR1 PCR and mPCR along with Southern blot, RT-qPCR, and FMRP levels to evaluate size- and methylation-mosaicism in 12 males with FXS (7 with FXS + ASD) [11]. They concluded that lower FMR1 mRNA and FMRP levels were the main contributors to cognitive impairment and that presence of a normal allele appeared to compensate in some but not all individuals. Pretto et al. [46] studied 18 patients with FXS (9 with FXS + ASD), including 7 with size- and 6 with methylation-mosaicism, demonstrating that FMR1 RNA and FMRP levels correlated in general with FMR1 methylation in peripheral blood cells and fibroblasts although there were differences in CGG expansion and blood samples showed lower methylation. They also reported that FSIQ scores were inversely correlated with level of methylation and directly with FMRP levels. However, other aspects of the neurobehavioral phenotype, such as number of seizures, and severity of hyperactivity or autistic behavior were not related to methylation or FMRP levels.

Considering the relatively consistent relationship between FMR1 methylation, FMR1 mRNA, and FMRP and the more direct phenotypical implications of protein expression, FMRP levels seem to be the most suitable molecular parameter for molecular-neurobehavioral analyses [1, 2]. Our findings confirm previous studies $[9,10,29,36]$ showing that FMRP is a biomarker of overall clinical severity in FXS that might help stratify patients with FXS in clinical trials [38]. We found a strong link between FMRP levels and IQ or level of ID [1, 7, 9-11, 19, 29, 36, 46], evident in male-female comparisons and in analysis of males with a range of clinical presentations. Nonetheless, the availability of a sensitive and precise assay such as qFMRP [43], allowed us to detect other phenotypical correlates of FMRP deficiency not reported in the aforementioned studies. For instance, we found two-fold lower levels of FMRP in males with FXS and ASD than in those with FXS-only, although there was a wide range of protein expression in the latter group. Nonetheless, this finding only held in males with mild-moderate ID, since in those with severe ID their even lower FMRP levels were independent of ASD status. Since marked decrease in FMRP is not only the basis for FXS but also a contributor to the ASD phenotype, as the signaling pathways of FMR1 and other genes linked to the behavioral disorder substantially overlap [23, 24, 28, 61], a more definitive answer about the relationship between FMRP levels and ASD status deserves further study. Other relationships between FMRP levels and neurobehavioral parameters included unspecified anxiety only in low functioning males with low FMRP and ASD and SA in females and higher functioning males without ASD but with higher FMRP levels. Overall, our study replicated an extremely high rate of anxiety in FXS reported in the literature regardless of gender [62]. Anxiety is intertwined in FXS [62, 63], and in FXS with ASD [36]. Two potentially clinically meaningful SA subgroups within the male-only group were identified with separately applied CGI-S SA scoring (CGI-S $\mathrm{ANX}_{\text {- }}$ - an approach which has also been used in a 
second-wave of clinical trials in FXS (i.e., the NCT03697161 gaboxadol recently completed study). Further study of anxiety in relationship to FMRP and ASD status in FXS may also help stratify patients with FXS in clinical trials [38].

As with ASD in males with severe ID, the relationship between FMRP levels and overall severe problem behavior (ABC-CFX total score $\geq 50$ ) was also cofounded with greater cognitive impairment. These findings are in line with the recognition, in recent years, of a more severe neurobehavioral phenotype mainly in males with FXS. This is characterized by severe ID, ASD diagnosis, and severe irritability, aggression, agitation, and self-injury types of behavior [25, 27, 64]. Indeed, our sample of males with FXS and ASD $[26,34]$ had significantly elevated $A B C-C_{F X}$ total scores driven by the Irritability subscale [65] that required use of atypical antipsychotic aripiprazole [66-68]. A presumed link between anxiety and $A B C-C_{F X}$ Irritability subscale in lower functioning individuals with FXS led experts in fragile $X$ field to include the latter as an outcome measure in cannabinol clinical trials in FXS (NCT03614663 and NCT03802799). Our findings suggest that the lowest FMRP levels seem to concentrate in this group of individuals. Availability of sensitive assays like qFMRP used here are key for advancing our understanding of the role of FMRP deficit in FXS, since threshold levels ( $<70 \%$ typical) for ID have been recently described [19] and delineating differences among those with the lowest levels will require high power discrimination.

\section{Limitations}

Although our study is, to our knowledge, the largest molecular-neurobehavioral correlation using multiple and sensitive FMR 1 and FMRP assays the sample size was relatively modest considering the variability and complexity of the molecular and phenotypical measures. Marked neurobehavioral differences between males and females with FXS, coupled with the well-known genetic differences inherent to Xlinked disorders (e.g. X-inactivation in females), complicated the molecular and correlational analyses. Given the size of the cohort, the necessity of combining size- and methylation-mosaicism limited the full appreciation of differences between these types of mosaicism. Despite the use of raw score-based zscore calculations for FSIQ and floor effects on cognitive or adaptive skills testing for some subjects were also a limitation for studying range of cognitive impairment. Lack of a formal anxiety measure also limited our ability of subtyping anxiety.

\section{Conclusions}

Our findings underscore the association between FMR1 CGG expansion, gene methylation, FMRP levels, and overall neurobehavioral severity. The complementarity of FMR1 genomic and protein parameters, and the concordance of blood and buccal profiles, support the benefit of characterizing and stratifying individuals with FXS according to their molecular profiles in observational and interventional studies. It also highlights the potential of molecular profiles, in particular FMRP levels, as a prognostic marker in FXS.

\section{Abbreviations}


ABAS-II and ABAS-III - Adaptive Behavior Assessment System Second and Third Editions; ABC- $\mathrm{C}_{\mathrm{FX}}-$ Aberrant Behavior Checklist-Community adapted for Fragile X; ADHD - Attention deficit hyperactivity disorder; AGE - Agarose gel electrophoresis; AGG - adenine-guanine-guanine; ASD - Autism Spectrum Disorders; ADOS - Autism Diagnostic Observation Schedule; CE - Capillary electrophoresis; CEB - Cell Extraction Buffer; CGI-S - Clinical Global Impression-Severity; CGI-S $_{A N X}$ - CGI applied to profile the severity/level of social anxiety; FM - full mutation; DAS - Differential Ability Scales; dF - Degrees of Freedom; FMRP - Fragile X mental retardation protein; FSIQ - full scale intelligence quotient; FX - fragile X; FXS - fragile X syndrome; gDNA - genomic DNA; GS-PCR - gene specific PSR; GS-PSR/AGE - gene specific PCR with products resolved by agarose gel electrophoresis; ID - intellectual disability; IQ intelligence quotient; IRB - Institutional Review Board; KKI - the Kennedy Krieger Institute; MMmethylation mosaicism; mPCR - methylation PCR; PBS - phosphate-buffered saline; PM - premutation; RIN - RNA Integrity Number; RP-PCR - Repeat-Primed PCR; RP-PCR/CE - Repeat primed PCR with products resolved by capillary electrophoresis; RT-qPCR - Reverse transcription quantitative PCR (or quantitative reverse transcription PCR); RFU - relative fluorescence units; RUMC - Rush University Medical Center; SAsocial anxiety; SB-5 - Stanford-Binet Intelligence Scales-5th Edition; SD - Standard Deviation; SIB-R Scales of Independent Behavior-Revised; VABS-II - Vineland Adaptive Behavior Scales-Second Edition; WB - whole blood; WISC-IV and WISC-V - Wechsler Intelligence Scale for Children, Fourth and Fifth Edition; WPPSI - Wechsler Preschool and Primary Scale of Intelligence.

\section{Declarations}

\section{Ethics approval and consent to participate}

Clinical samples were procured from patients that were evaluated at KKI or RUMC, following informed consent and according to protocols approved by IRB.

For samples from KKI, Johns Hopkins Medicine IRB approved the study (IRB NA_ 00082793).

For the samples obtained at RUMC, the study was approved by the RUMC IRB and informed consent was obtained from all guardians

Consent for publication: Not applicable

\section{Availability of data and materials}

Data availability statement: All data analyzed during this study are included in this published article and its supplementary information files.

\section{Competing interests}

DBB has received funding from Seaside, Roche, Neuren, Pfizer, Shire, Lundbeck, Forest, Sunovion, SyneuRX, Alcobra, Akili, Medgenics, Purdue, Supernus as a main sub-investigator, and Ovid and Zynerba Pharmaceuticals as a principal investigator on clinical trials. He also consulted on clinical trial outcome 
measures (Seaside, Ovid). All the above funding has been directed to Kennedy Krieger Institute/the Johns Hopkins Medical Institutions; DBB receives no personal funds and the Institute has no relevant financial interest in any of the commercial entities listed. AS, SFS, EB, KN, KJ, AH, and GJL are or were employed by Asuragen at the time the work was performed and have or may have stock options in the company. GJL, $\mathrm{EB}$ and $\mathrm{AH}$ are inventors on one or more patents or patent applications associated with genotyping or epityping FMR1 molecular features. EBK has received funding from Acadia, Alcobra, AMO, Asuragen, BioMarin, Cydan, Fulcrum, GeneTx, GW, Ionis, Lumos, Marinus, Neuren, Neurotrope, Novartis, Ovid, Roche, Seaside Therapeutics, Ultragenyx, Vtesse/Sucampo/Mallinckrodt, Yamo, and Zynerba Pharmaceuticals to consult on clinical trial design, run clinical trials or develop testing standards or biomarkers, all of which is directed to RUMC in support of rare disease programs; EBK receives no personal funds and RUMC has no relevant financial interest in any of the commercial entities listed. GL and WTB declare no conflict of interest for the patent "System and Method for Quantifying Fragile X Mental 1Protein in tissue and blood samples" (United States Patent \# 8628934). WEK receives no personal funds and has no relevant financial interest in any of the commercial entities listed. He is Chief Medical Officer of Anavex Life Sciences Corp. and has been consultant to AveXis, EryDel, GW, Marinus, Neuren, Newron, Ovid, Stalicla, and Zynerba. The other co-authors declare that they have no competing interests.

\section{Funding}

We acknowledge NICHD grant 1R43HD082900-01A1 (Latham PI), subcontract to Kennedy Krieger Institute (PI: Budimirovic).

\section{Authors' contributions}

DBB and GJL were responsible for the initial conceptualization of the study. DBB was responsible for patients' recruitment and retention. He extensively reviewed the data and executed the design of this manuscript, participated in the interpretation of the data, initially drafted the manuscript developed and modified the tables throughout, critically revised the manuscript and was responsible for its final content, and primarily coordinated all necessary efforts among coauthors on the manuscript throughout the process. AS and GJL drafted the manuscript developed, wrote and revised the subsections of the manuscript, assisted with the design of the manuscript, generated references in endnote and applied them in the body text. AS, SFS, and GJL were responsible for data management, the statistical analyses and preparation of the Figures. EB, SFS, KN, KC, KJ, AH and GJL were all responsible for lab analyses, data collection and interpretation. DDP participated in statistical analyses, interpretation of the data, modified the tables throughout, helped with clinical data management and submission process. EMM has generated an extended raw scores analyses of FSIQ scores and critically reviewed the manuscript. TA, GLF, CD and TB were responsible for lab analyses. KS, LZ and EBK were responsible for collection of control samples and EBK oversaw data collection, participated in interpretation of the data, and critically reviewed and revised the manuscript, and helped to finalize it. WEK critically reviewed and participated in interpretation of the data, statistical analyses, and helped to revise and finalize the manuscript. GJL critically reviewed, revised the manuscript, assisted with the design of the manuscript, helped to finalize 
manuscript, participated in interpretation of the data and coordinated efforts among other coauthors when necessary.

The authors read and approved the final manuscript.

\section{Acknowledgements}

Clinical Trials Unit staff and phlebotomists at the Institute. Anca Toma, MD and Haley Province, MD/PhD candidate for their assistance with the manuscripts technical support, including their proofreading effort.

Since 2013 , these results were presented at following conferences: $1^{\text {st }}$ through $4^{\text {th }}$ International Conference on FMR1 premutation in 2013, 2015, 2017 and 2019, respectively; ACMG Annual Clinical Genetics Meeting 2014; $15^{\text {th }}$ and $16^{\text {th }}$ International Fragile X Conferences in 2016 and 2018, respectively; Gordon Research Conference "Fragile X and Autism-Related Disorders" in 2016; International Conference on Autism and Fragile-X Associated Disorders in 2019, and American Academy of Child \& Adolescent Psychiatry Annual Meeting in 2019.

\section{Additional materials}

File name: Additional file 1

Title of data: Clinical description and summary of molecular testing results for $31 \mathrm{FM}$ patients

Description of data: Clinical description (gender, age, level of intellectual disability, estimated extended FISQ, presence of ASD) and summary of molecular testing (FMRP levels, and FMR1 size and methylation data) for 26 male and 5 female full mutation patients.

* In order to address a skewed effect of the FSIQ-standard score testing, raw-data based subscores were applied instead by a senior neuropsychologist, which allowed an extended FSIQ score to be generated. Briefly, if the SB-5 subtests raw scores were available, they were used for the extended FSIQ scoring. If other than aforementioned IQ standard tests were available, those raw scores were used to estimate the extended FSIQ. When there were several administrations of different tests, the most current administration was used for the consensus. Alternatively, if the scores were highly discrepant, estimation was made somewhere in the middle of the two raw data-based scores.

** Level of methylation mosaicism was evaluated for 26 male FM patients and scored as: 1-not detected, 2-low level of mosaicism, and 3-high level of mosaicism, based on relative intensities of unmethylated or partially methylated peaks compared to fully methylated peaks from FMR1 mPCR test.

\section{References}

1. Kaufmann WE, Reiss AL. Molecular and cellular genetics of fragile X syndrome. Am J Med Genet. 1999;88(1):11-24. 
2. Bagni C, Tassone F, Neri G, Hagerman R. Fragile X syndrome: causes, diagnosis, mechanisms, and therapeutics. J Clin Invest. 2012;122(12):4314-22.

3. Gholizadeh S, Halder SK, Hampson DR. Expression of fragile X mental retardation protein in neurons and glia of the developing and adult mouse brain. Brain Res. 2015;1596:22-30.

4. Banerjee A, Ifrim MF, Valdez AN, Raj N, Bassell GJ. Aberrant RNA translation in fragile X syndrome: From FMRP mechanisms to emerging therapeutic strategies. Brain Res. 2018;1693(Pt A):24-36.

5. Darnell JC, Klann E. The translation of translational control by FMRP: therapeutic targets for FXS. Nat Neurosci. 2013;16(11):1530-6.

6. Sidorov MS, Auerbach BD, Bear MF. Fragile X mental retardation protein and synaptic plasticity. Mol Brain. 2013;6:15.

7. Baker EK, Arpone M, Aliaga Vera S, Bretherton L, Ure A, Kraan CM, et al. Intellectual Functioning and Behavioural Features Associated With Mosaicism in Fragile X Syndrome. J Neurodev Disord. 2019;11(1):41.

8. Lessard M, Chouiali A, Drouin R, Sebire G, Corbin F. Quantitative measurement of FMRP in blood platelets as a new screening test for fragile X syndrome. Clin Genet. 2012;82(5):472-7.

9. Loesch DZ, Huggins RM, Hagerman RJ. Phenotypic variation and FMRP levels in fragile X. Ment Retard Dev Disabil Res Rev. 2004;10(1):31-41.

10. Kaufmann WE, Abrams MT, Chen W, AL R. Genotype, Molecular Phenotype, and Cognitive Phenotype: Correlations in Fragile X Syndrome. Am J Med Genet. 1999;83(4):286-95.

11. Jiraanont P, Kumar M, Tang HT, Espinal G, Hagerman PJ, Hagerman RJ, et al. Size and methylation mosaicism in males with Fragile X syndrome. Expert Rev Mol Diagn. 2017;17(11):1023-32.

12. Nolin SL, Glicksman A, Houck GE, Jr., Brown WT, Dobkin CS. Mosaicism in fragile $X$ affected males. Am J Med Genet. 1994;51(4):509-12.

13. Tassone F, Hagerman RJ, Gane LW, Taylor AK. Strong similarities of the FMR1 mutation in multiple tissues: postmortem studies of a male with a full mutation and a male carrier of a premutation. Am J Med Genet. 1999;84(3):240-4.

14. Dobkin CS, Nolin SL, Cohen I, Sudhalter V, Bialer MG, Ding XH, et al. Tissue differences in fragile X mosaics: mosaicism in blood cells may differ greatly from skin. Am J Med Genet. 1996;64(2):296301.

15. Hagerman RJ, Hull CE, Safanda JF, Carpenter I, Staley LW, O'Connor RA, et al. High functioning fragile $X$ males: demonstration of an unmethylated fully expanded FMR-1 mutation associated with protein expression. Am J Med Genet. 1994;51(4):298-308.

16. Taylor AK, Tassone F, Dyer PN, Hersch SM, Harris JB, Greenough WT, et al. Tissue heterogeneity of the FMR1 mutation in a high-functioning male with fragile X syndrome. Am J Med Genet. 1999;84(3):233-9.

17. Maddalena A, Yadvish KN, Spence WC, Howard-Peebles PN. A fragile X mosaic male with a cryptic full mutation detected in epithelium but not in blood. Am J Med Genet. 1996;64(2):309-12. 
18. Ciaccio C, Fontana L, Milani D, Tabano S, Miozzo M, Esposito S. Fragile X syndrome: a review of clinical and molecular diagnoses. Ital J Pediatr. 2017;43(1):39.

19. Kim K, HessI D, Randol JL, Espinal GM, Schneider A, Protic D, et al. Association between IQ and FMR1 protein (FMRP) across the spectrum of CGG repeat expansions. PLoS One. 2019;14(12):e0226811.

20. Chen L, Hadd A, Sah S, Filipovic-Sadic S, Krosting J, Sekinger E, et al. An information-rich CGG repeat primed PCR that detects the full range of fragile $X$ expanded alleles and minimizes the need for southern blot analysis. J Mol Diagn. 2010;12(5):589-600.

21. Filipovic-Sadic S, Sah S, Chen L, Krosting J, Sekinger E, Zhang W, et al. A novel FMR1 PCR method for the routine detection of low abundance expanded alleles and full mutations in fragile $X$ syndrome. Clin Chem. 2010;56(3):399-408.

22. Yrigollen CM, Martorell L, Durbin-Johnson B, Naudo M, Genoves J, Murgia A, et al. AGG interruptions and maternal age affect FMR1 CGG repeat allele stability during transmission. J Neurodev Disord. 2014;6(1):24.

23. Kover ST, Pierpont El, Kim JS, Brown WT, Abbeduto L. A neurodevelopmental perspective on the acquisition of nonverbal cognitive skills in adolescents with fragile $X$ syndrome. Dev Neuropsychol. 2013;38(7):445-60.

24. Hagerman RJ, Polussa J. Treatment of the psychiatric problems associated with fragile $X$ syndrome. Curr Opin Psychiatry. 2015;28(2):107-12.

25. Kaufmann WE, Kidd SA, Andrews HF, Budimirovic DB, Esler A, Haas-Givler B, et al. Autism Spectrum Disorder in Fragile X Syndrome: Cooccurring Conditions and Current Treatment. Pediatrics. 2017;139(Suppl 3):S194-S206.

26. Budimirovic D, Haas-Givler B, Blitz R, Esler A, Kaufmann W, Sudhalter V, et al. Consensus of the Fragile X Clinical and Research Consortium on Clinical Practices: Autism Spectrum Disorder In Fragile X Syndrome 2014:[1-15 pp.]. Available from: https://fragilex.org/wpcontent/uploads/2012/08/Autism-Spectrum-Disorder-in-Fragile-X-Syndrome-2014-Nov.pdf.

27. Budimirovic DB, Kaufmann WE. What can we learn about autism from studying fragile $X$ syndrome? Dev Neurosci. 2011;33(5):379-94.

28. Bagni C, Zukin RS. A Synaptic Perspective of Fragile X Syndrome and Autism Spectrum Disorders. Neuron. 2019;101(6):1070-88.

29. Loesch DZ, Bui QM, Dissanayake C, Clifford S, Gould E, Bulhak-Paterson D, et al. Molecular and Cognitive Predictors of the Continuum of Autistic Behaviours in Fragile X. Neurosci Biobehav Rev. 2007;31(3):315-26.

30. Ascano M, Mukherjee N, Bandaru P, Miller JB, Nusbaum JD, Corcoran DL, et al. FMRP targets distinct mRNA sequence elements to regulate protein expression. Nature. 2012;492(7429):382-6.

31. Iossifov I, Ronemus M, Levy D, Wang Z, Hakker I, Rosenbaum J, et al. De novo gene disruptions in children on the autistic spectrum. Neuron. 2012;74(2):285-99.

32. Kaufmann WE, Capone GT, Clarke M, Budimirovic DB. Autism in Genetic Intellectual Disability: Insights into Idiopathic Autism. Totowa, NJ The Humana Press Inc.; 2008. 
33. Fatemi SH, Folsom TD. The role of fragile X mental retardation protein in major mental disorders. Neuropharmacology. 2011;60(7-8):1221-6.

34. Budimirovic DB, Subramanian M. Neurobiology of Autism and Intellectual Disability: Fragile $X$ Syndrome. Neurobiology of Disease 2nd ed. New York: Oxford University Press; 2016. p. 375-84.

35. Hagerman RJ, Berry-Kravis E, Hazlett HC, Bailey DB, Moine H, Kooy RF, et al. Fragile X syndrome. Nat Rev Dis Primers. 2017;3:17065.

36. Niu M, Han Y, Dy ABC, Du J, Jin H, Qin J, et al. Autism Symptoms in Fragile X Syndrome. J Child Neurol. 2017;32(10):903-9.

37. Zafarullah M, Tassone F. Molecular Biomarkers in Fragile X Syndrome. Brain Sci. 2019;9(5):96.

38. Budimirovic DB, Berry-Kravis E, Erickson CA, Hall SS, HessI D, Reiss AL, et al. Updated report on tools to measure outcomes of clinical trials in fragile $X$ syndrome. J Neurodev Disord. 2017;9:14.

39. Chen L, Hadd AG, Sah S, Houghton JF, Filipovic-Sadic S, Zhang W, et al. High-resolution methylation polymerase chain reaction for fragile $X$ analysis: evidence for novel FMR1 methylation patterns undetected in Southern blot analyses. Genet Med. 2011;13(6):528-38.

40. Nolin SL, Glicksman A, Ding X, Ersalesi N, Brown WT, Sherman SL, et al. Fragile X analysis of 1112 prenatal samples from 1991 to 2010. Prenat Diagn. 2011;31(10):925-31.

41. Nolin SL, Sah S, Glicksman A, Sherman SL, Allen E, Berry-Kravis E, et al. Fragile X AGG analysis provides new risk predictions for 45-69 repeat alleles. Am J Med Genet A. 2013;161A(4):771-8.

42. Gustin SLF, Wang G, Baker VM, Latham G, Sebastiano V. Use of human-derived stem cells to create a novel, in vitro model designed to explore FMR1 CGG repeat instability amongst female premutation carriers. J Assist Reprod Genet. 2018.

43. LaFauci G, Adayev T, Kascsak R, Kascsak R, Nolin S, Mehta P, et al. Fragile X screening by quantification of FMRP in dried blood spots by a Luminex immunoassay. $J$ Mol Diagn. 2013;15(4):508-17.

44. Hadd AG, Filipovic-Sadic S, Zhou L, Williams A, Latham GJ, Berry-Kravis E, et al. A methylation PCR method determines FMR1 activation ratios and differentiates premutation allele mosaicism in carrier siblings. Clin Epigenetics. 2016;8:130.

45. Nolin SL, Glicksman A, Ersalesi N, Dobkin C, Brown WT, Cao R, et al. Fragile X full mutation expansions are inhibited by one or more AGG interruptions in premutation carriers. Genet Med. 2015;17(5):358-64.

46. Pretto D, Yrigollen CM, Tang HT, Williamson J, Espinal G, Iwahashi CK, et al. Clinical and molecular implications of mosaicism in FMR1 full mutations. Front Genet. 2014;5:318.

47. Adayev T, LaFauci G, Dobkin C, Caggana M, Wiley V, Field M, et al. Fragile X protein in newborn dried blood spots. BMC Med Genet. 2014;15:119.

48. Latham GJ, Coppinger J, Hadd AG, Nolin SL. The role of AGG interruptions in fragile X repeat expansions: a twenty-year perspective. Front Genet. 2014;5:244. 
49. Grasso M, Boon EM, Filipovic-Sadic S, van Bunderen PA, Gennaro E, Cao R, et al. A novel methylation PCR that offers standardized determination of FMR1 methylation and CGG repeat length without southern blot analysis. J Mol Diagn. 2014;16(1):23-31.

50. Tassone F, Pan R, Amiri K, Taylor AK, Hagerman PJ. A rapid polymerase chain reaction-based screening method for identification of all expanded alleles of the fragile X (FMR1) gene in newborn and high-risk populations. J Mol Diagn. 2008;10(1):43-9.

51. Association AP. Diagnostic and statistical manual of mental disorders (5th ed.). Arlington, VA2013.

52. Sansone SM, Widaman KF, Hall SS, Reiss AL, Lightbody A, Kaufmann WE, et al. Psychometric study of the Aberrant Behavior Checklist in Fragile X Syndrome and implications for targeted treatment. J Autism Dev Disord. 2012;42(7):1377-92.

53. Sansone SM, Schneider A, Bickel E, Berry-Kravis E, Prescott C, HessI D. Improving IQ measurement in intellectual disabilities using true deviation from population norms. J Neurodev Disord. 2014;6(1):16.

54. Budimirovic DB, Bukelis I, Cox C, Gray RM, Tierney E, Kaufmann WE. Autism spectrum disorder in Fragile $X$ syndrome: differential contribution of adaptive socialization and social withdrawal. Am J Med Genet A. 2006;140A(17):1814-26.

55. Eichler EE, Holden JJ, Popovich BW, Reiss AL, Snow K, Thibodeau SN, et al. Length of uninterrupted CGG repeats determines instability in the FMR1 gene. Nat Genet. 1994;8(1):88-94.

56. Cohen IL, Nolin SL, Sudhalter V, Ding XH, Dobkin CS, Brown WT. Mosaicism for the FMR1 gene influences adaptive skills development in fragile X-affected males. Am J Med Genet. 1996;64(2):3659.

57. Juusola JS, Anderson P, Sabato F, Wilkinson DS, Pandya A, Ferreira-Gonzalez A. Performance evaluation of two methods using commercially available reagents for PCR-based detection of FMR1 mutation. J Mol Diagn. 2012;14(5):476-86.

58. Seneca S, Lissens W, Endels K, Caljon B, Bonduelle M, Keymolen K, et al. Reliable and sensitive detection of fragile $X$ (expanded) alleles in clinical prenatal DNA samples with a fast turnaround time. J Mol Diagn. 2012;14(6):560-8.

59. Genç B, Müller-Hartmann H, Zeschnigk M, Deissler H, Schmitz B, Majewski F, et al. Methylation Mosaicism of 5'-(CGG)(n)-3' Repeats in Fragile X, Premutation and Normal Individuals. Nucleic Acids Res. 2000;28(10):2141-52.

60. Bonarrigo FA, Russo S, Vizziello P, Menni F, Cogliati F, Giorgini V, et al. Think About It: FMR1 Gene Mosaicism. J Child Neurol. 2014;29(9):NP74-7.

61. Steinberg J, Webber C. The roles of FMRP-regulated genes in autism spectrum disorder: single- and multiple-hit genetic etiologies. Am J Hum Genet. 2013;93(5):825-39.

62. Cordeiro L, Ballinger E, Hagerman R, HessI D. Clinical assessment of DSM-IV anxiety disorders in fragile X syndrome: prevalence and characterization. J Neurodev Disord. 2011;3(1):57-67.

63. Talisa VB, Boyle L, Crafa D, Kaufmann WE. Autism and anxiety in males with fragile X syndrome: an exploratory analysis of neurobehavioral profiles from a parent survey. Am J Med Genet A. 2014;164A(5):1198-203. 
64. Eckert EM, Dominick KC, Pedapati EV, Wink LK, Shaffer RC, Andrews H, et al. Pharmacologic Interventions for Irritability, Aggression, Agitation and Self-Injurious Behavior in Fragile X Syndrome: An Initial Cross-Sectional Analysis. J Autism Dev Disord. 2019.

65. Berry-Kravis E, Hagerman R, Visootsak J, Budimirovic D, Kaufmann WE, Cherubini M, et al. Arbaclofen in fragile X syndrome: results of phase 3 trials. J Neurodev Disord. 2017;9:3.

66. Kucka M, Tomic M, Bjelobaba I, Stojilkovic SS, Budimirovic DB. Paliperidone and aripiprazole differentially affect the strength of calcium-secretion coupling in female pituitary lactotrophs. Sci Rep. 2015;5:8902.

67. Berry-Kravis E, Sumis A, Hervey C, Mathur S. Clinic-based retrospective analysis of psychopharmacology for behavior in fragile x syndrome. Int J Pediatr. 2012;2012:843016.

68. Erickson CA, Stigler KA, Wink LK, Mullett JE, Kohn A, Posey DJ, et al. A Prospective Open-Label Study of Aripiprazole in Fragile X Syndrome. Psychopharmacology (Berl). 2011;216(1):85-90.

\section{Figures}



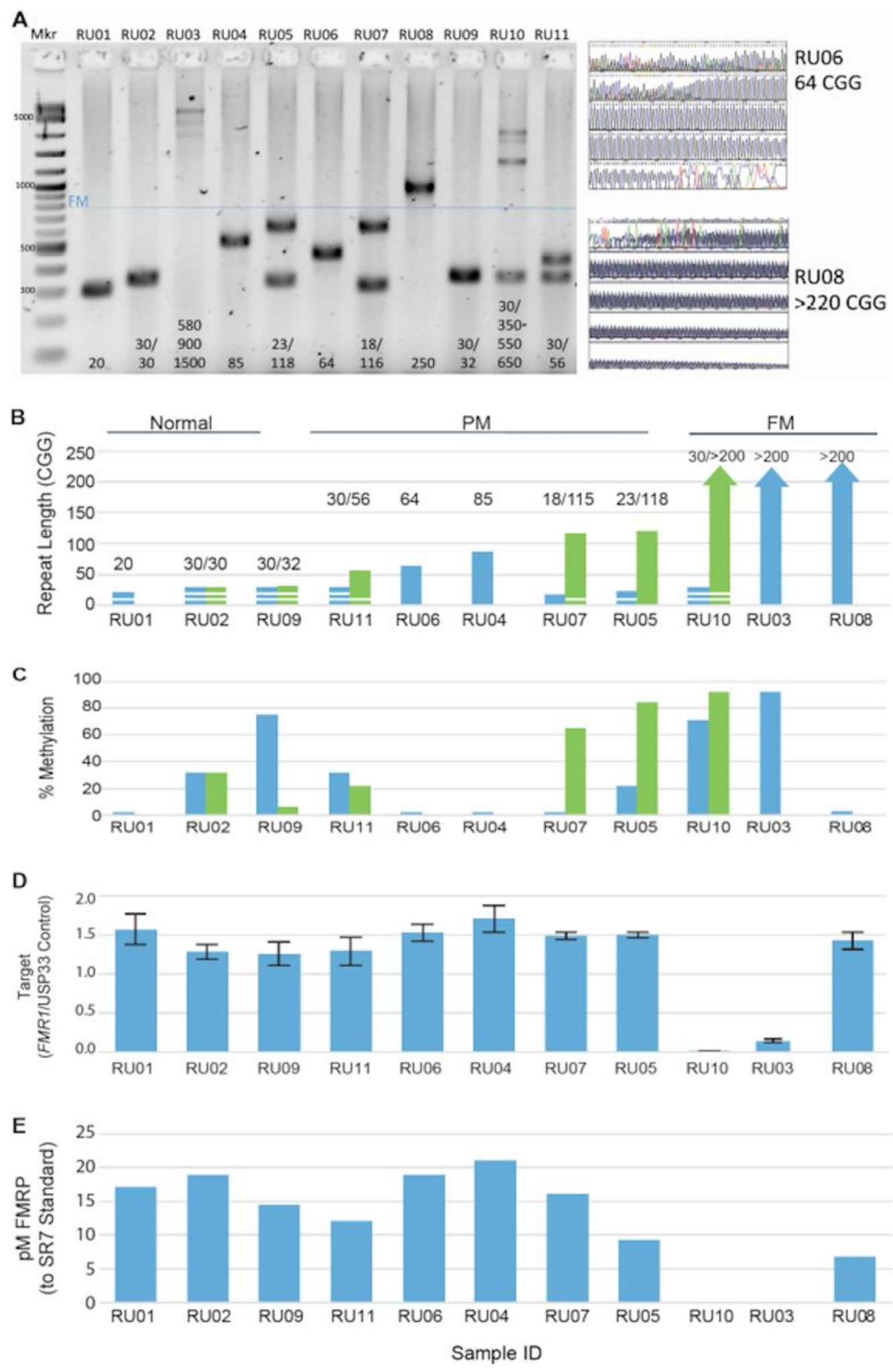

Figure 1

(A) GS-PCR/AGE and Sanger sequencing for repeat sizing range, (B) Repeat sizing (as determined by RP$P C R / C E$ ) and AGG interruptions (represented as horizontal column breaks, determined using Xpansion Interpreter PCR), (C) Methylation percentage assessed with mPCR/CE, (D) FMR1 mRNA expression levels for matched cell lines (RT-qPCR), and (E) FMRP levels normalized to the recombinant FMRP peptide GSTSR7. 


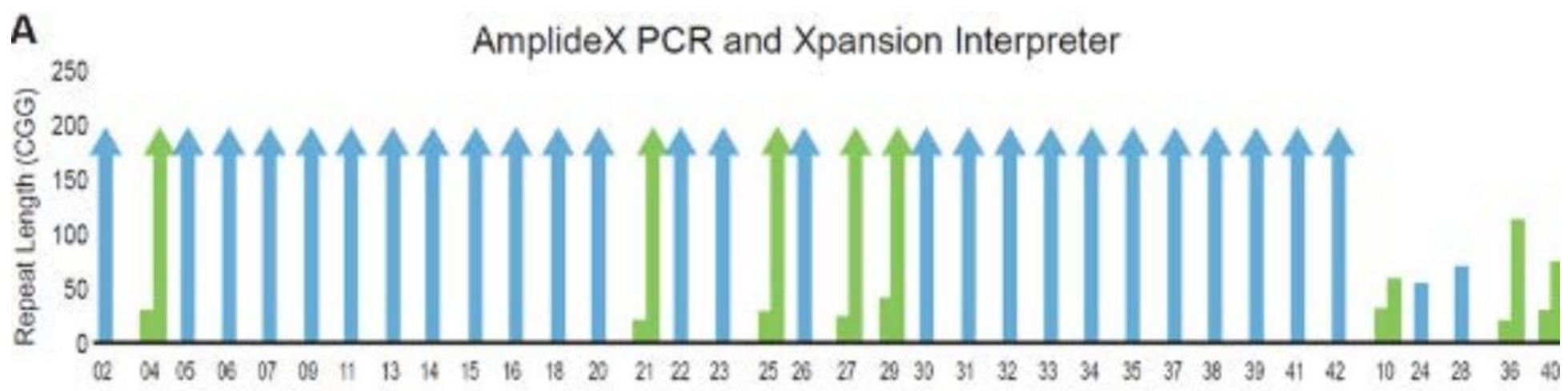

\section{B}

AmplideX mPCR
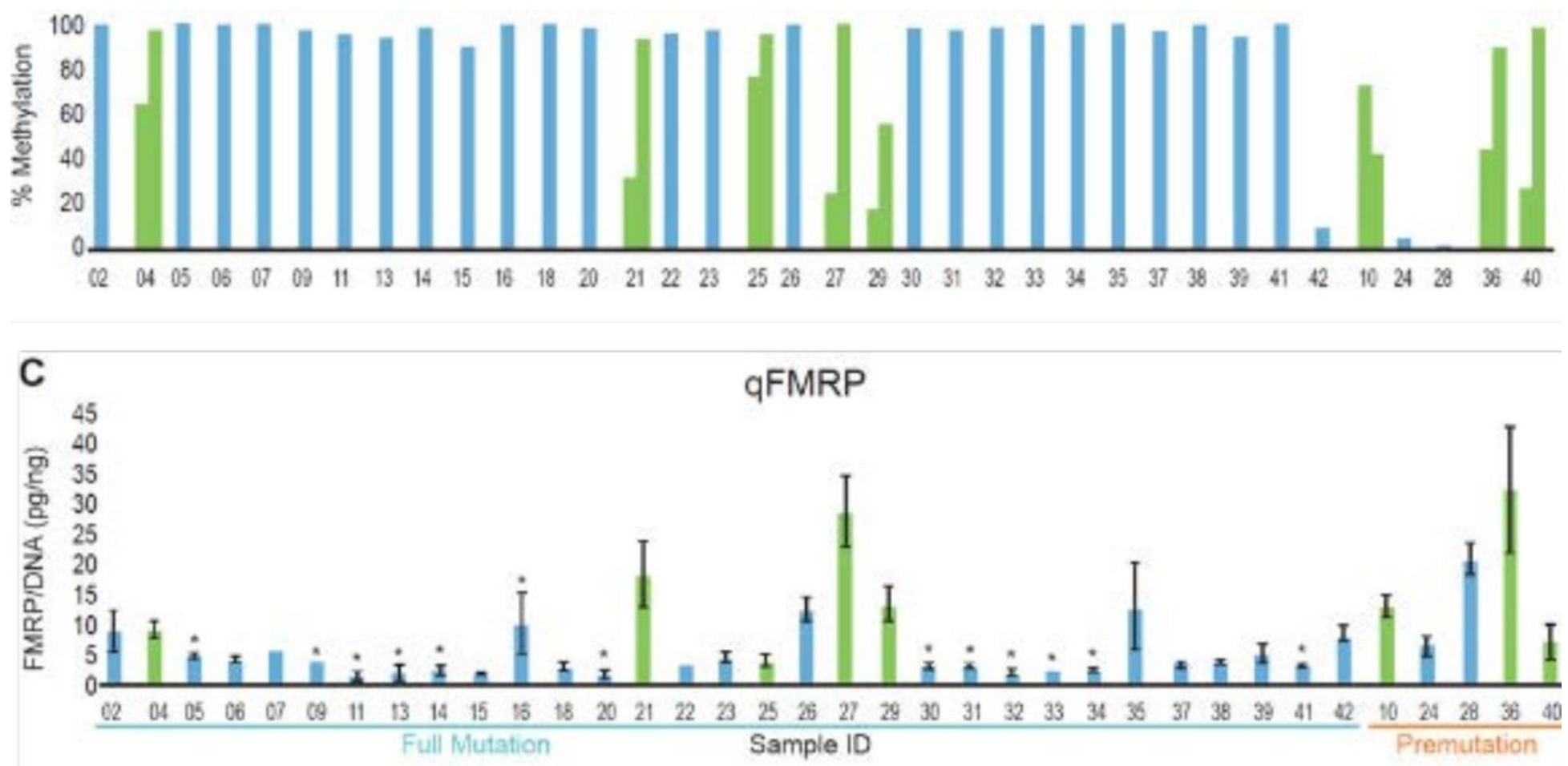

Figure 2

(A) FMR1 genotype (top panel) and (B) methylation status (middle panel) correlated with (C) FMRP levels (lower panel). Samples were annotated for FMR1 CGG repeat length and degree of methylation using AmplideX PCR/CE FMR1 and mPCR technologies. Male and female samples are colored in blue and green, respectively. Bottom panel: Error bars represent standard deviations. 
A

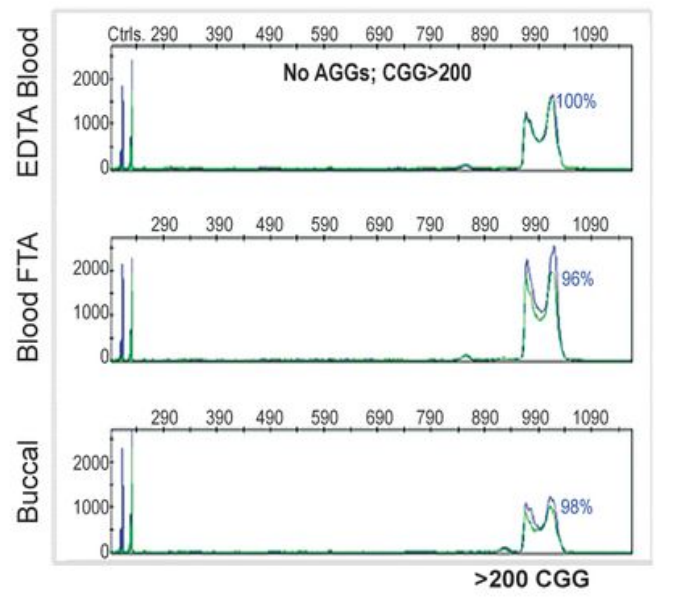

B
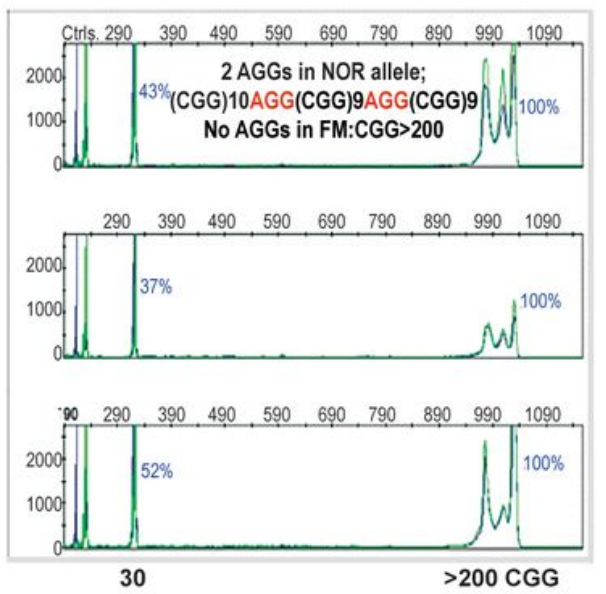

C
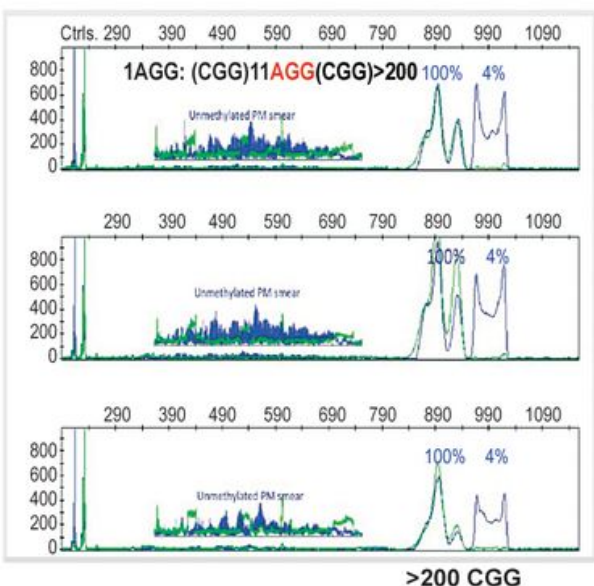

\section{Figure 3}

Blood samples collected in EDTA tubes or spotted on FTA paper used only for DNA analyses were compared with cheek swab specimens. DNA analyses from three representative FM subjects are shown. (A) Male with FXS (sample 09) with a fully methylated expansion and no detectable size or methylation mosaicism. (B) Female with FXS (sample 19) with random X-inactivation of the normal allele and a fully methylated FM allele. (C) Male with FXS (sample 02) with FM, PM size and methylation mosaicism in both blood and buccal gDNA. Capillary electrophoresis traces show CGG repeat length (blue, undigested) and methylation status (green, digested).
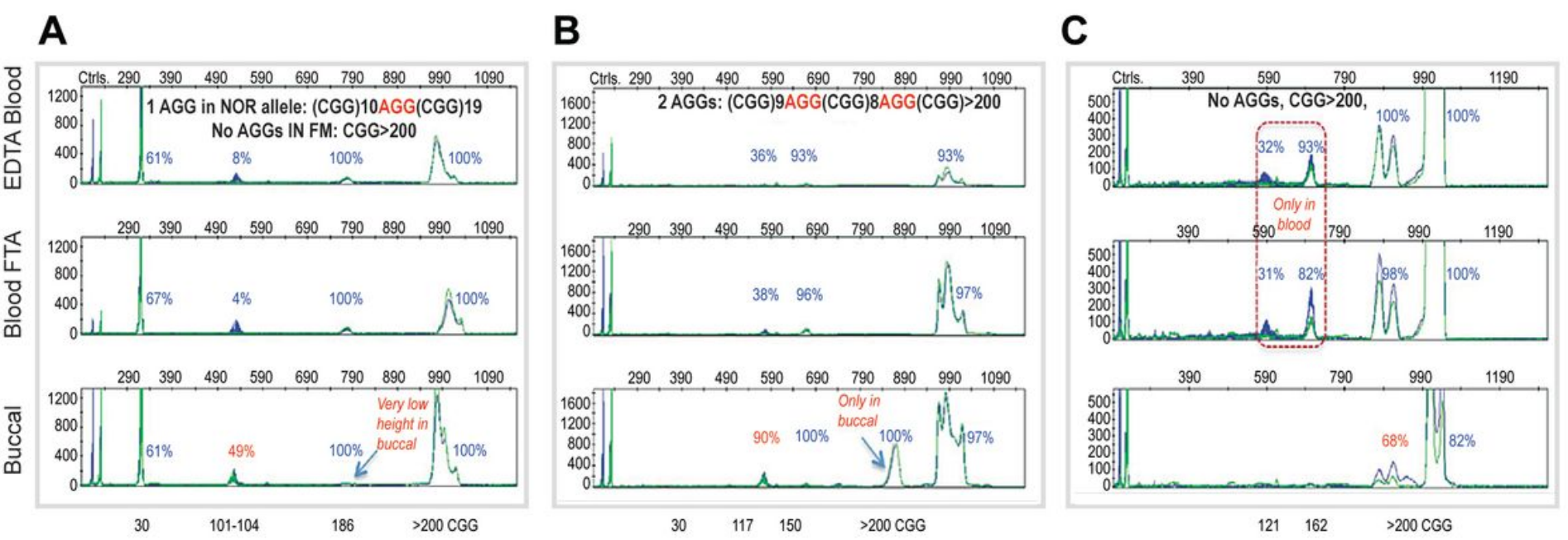

\section{Figure 4}

Level of concordance in primary allele CGG sizing and methylation status in blood and buccal specimen from subjects with FXS. (A) Female with FXS (sample 04) with PM size mosaicism and differential relative methylation in blood and buccal gDNA. (B) Male with FXS (sample 06) with an additional FM peak in buccal cells compared to blood, along with methylation mosaicism. (C) Male with FXS (sample 15) with a blood-only PM size mosaicism and reduced relative methylation of the FM in the buccal 
sample. Capillary electrophoresis traces show CGG repeat length (blue, undigested) and methylation status (green, digested).

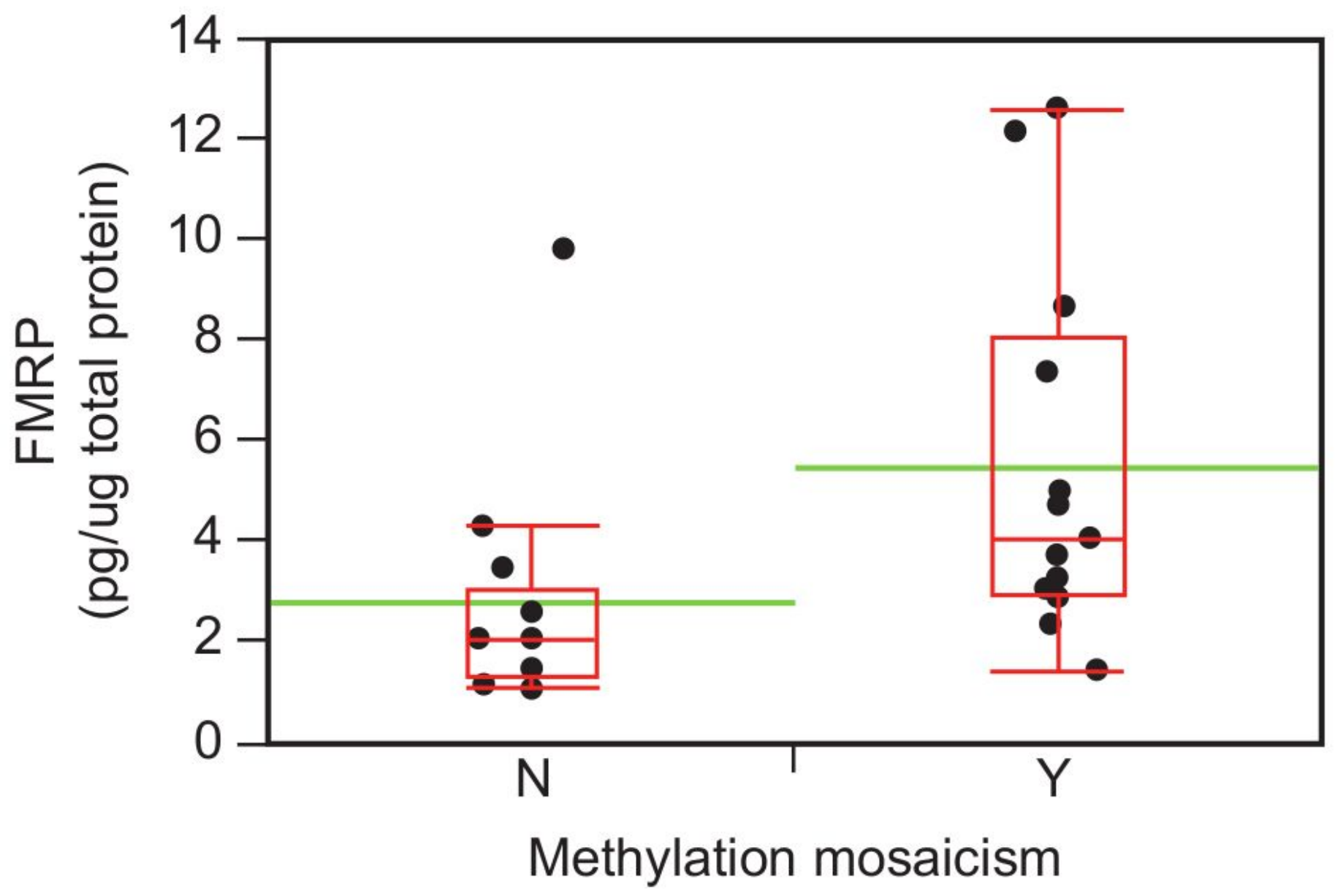

Figure 5

FMRP levels and methylation mosaicism (MM) status. In the FM-FMRP Subcohort males $(N=26)$, those with MM $(Y)$ had significantly higher FMRP levels as measured by the qFMRP assay. One-way ANOVA ( $p$ $=0.02)$, where the green line shows the mean for each group, and box plots represent the median and quantiles. $\mathrm{Y}$ (yes), $\mathrm{N}$ (no) methylation mosaicism. 


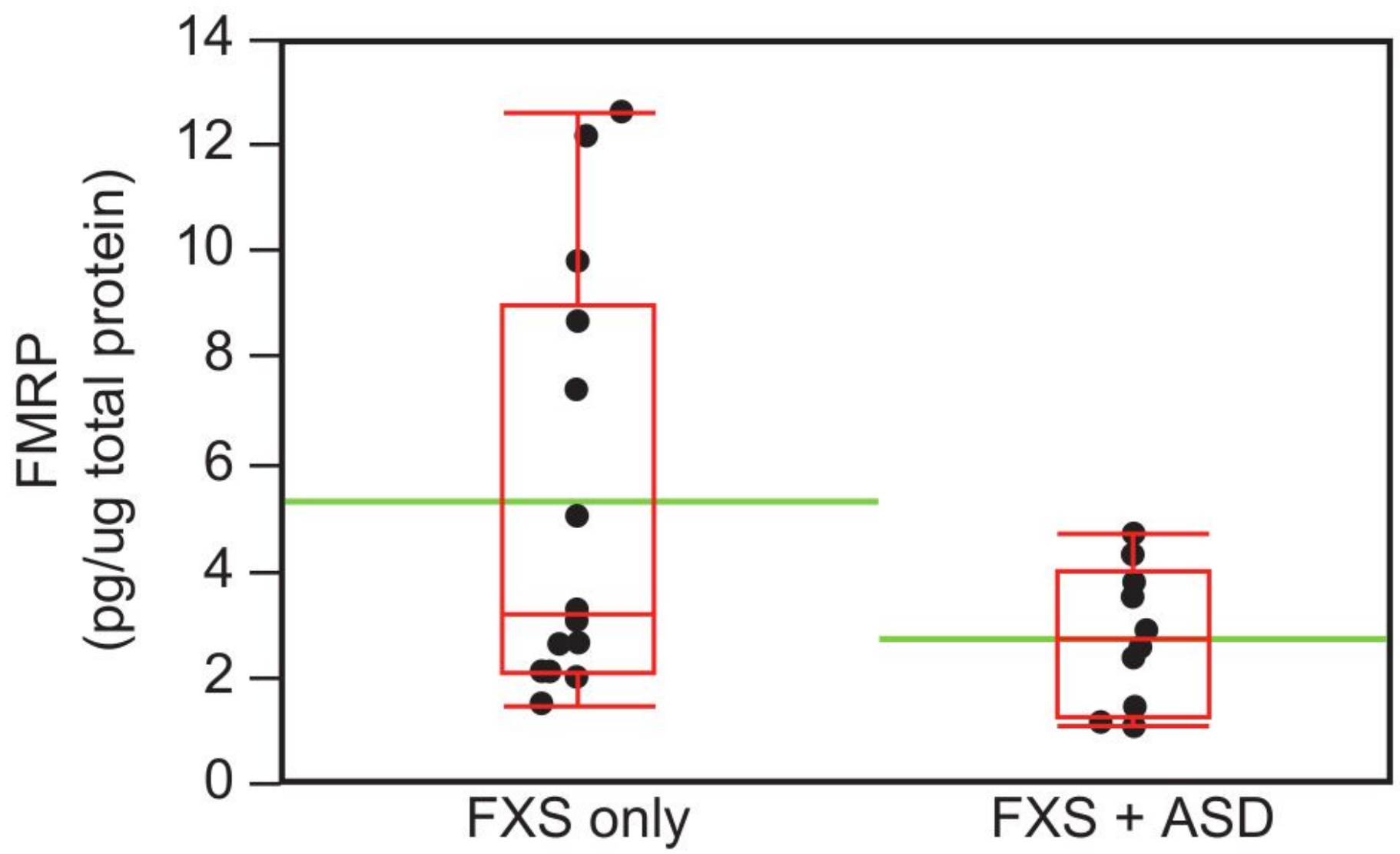

Figure 6

FMRP levels in males with FXS with and without ASD. qFMRP measurements showed significantly higher levels in the FXS-only group than in those with FXS + ASD ( $p=0.04$, Welch's t-test). The box plots outline median and percentiles 25 and 75 for each group, while the green line represents the mean for each group.

\section{Supplementary Files}

This is a list of supplementary files associated with this preprint. Click to download.

- Additionalfile1.xlsx 